OPEN ACCESS

Edited by:

Antonio Colantuoni,

University of Naples Federico II, Italy

Reviewed by:

Dominga Lapi,

University of Naples Federico II, Italy

Simona Damiano,

University of Naples Federico II, Italy

${ }^{*}$ Correspondence:

Henrique Silva

henrique.silva@ulusofona.pt

Specialty section:

This article was submitted to

Vascular Physiology,

a section of the journal

Frontiers in Physiology

Received: 16 August 2020

Accepted: 19 October 2020

Published: 27 November 2020

Citation:

Silva $\mathrm{H}$ and Lopes NMF (2020) Cardiovascular Effects of Caffeic Acid and Its Derivatives: A Comprehensive

Review. Front. Physiol. 11:595516.

doi: 10.3389/fphys.2020.595516

\section{Cardiovascular Effects of Caffeic Acid and Its Derivatives: A Comprehensive Review}

\author{
Henrique Silva ${ }^{1,2 *}$ and Nuno Miguel F. Lopes ${ }^{2}$ \\ ${ }^{1}$ CBIOS - Universidade Lusófona's Research Center for Biosciences and Health Technologies, Lisboa, Portugal, \\ ${ }^{2}$ Department of Pharmacological Sciences, Faculty of Pharmacy, Universidade de Lisboa, Lisbon, Portugal
}

Caffeic acid (CA) and its phenethyl ester (CAPE) are naturally occurring hydroxycinnamic acids with an interesting array of biological activities; e.g., antioxidant, anti-inflammatory, antimicrobial and cytostatic. More recently, several synthetic analogs have also shown similar properties, and some with the advantage of added stability. The actions of these compounds on the cardiovascular system have not been thoroughly explored despite presenting an interesting potential. Indeed the mechanisms underlying the vascular effects of these compounds particularly need clarifying. The aim of this paper is to provide a comprehensive and up-to-date review on current knowledge about CA and its derivatives in the cardiovascular system. Caffeic acid, CAPE and the synthetic caffeic acid phenethyl amide (CAPA) exhibit vasorelaxant activity by acting on the endothelial and vascular smooth muscle cells. Vasorelaxant mechanisms include the increased endothelial NO secretion, modulation of calcium and potassium channels, and modulation of adrenergic receptors. Together with a negative chronotropic effect, vasorelaxant activity contributes to lower blood pressure, as several preclinical studies show. Their antioxidant, anti-inflammatory and anti-angiogenic properties contribute to an important anti-atherosclerotic effect, and protect tissues against ischemia/reperfusion injuries and the cellular dysfunction caused by different physicochemical agents. There is an obvious shortage of in vivo studies to further explore these compounds' potential in vascular physiology. Nevertheless, their favorable pharmacokinetic profile and overall lack of toxicity make these compounds suitable for clinical studies.

Keywords: caffeic acid derivatives, vasorelaxant, blood pressure, antioxidants, cardiovascular protection

\section{INTRODUCTION}

Caffeic acid (CA) is a hydroxycinnamic acid that belongs to the phenolic acid family of polyphenols. It is the main hydroxycinnamic acid present in the human diet, with the highest content being found in blueberries, kiwis, plums, cherries, and apples, although also present in cereals, carrots, salad, eggplants, cabbage, artichoke, and coffee (El-Seedi et al., 2012; Del Rio et al., 2013; Sova and Saso, 2020). Besides foodstuffs, CA is also present in propolis, a resinous mixture created by honeybees from different botanical sources and a natural product that has been used in folk 
medicine for many centuries (Silva et al., 2014). Caffeic acid phenethyl ester (CAPE) is a naturally occurring derivative of $\mathrm{CA}$ and is also prevalent in propolis, mainly in the poplar variety, made from resinous exudates of buds and young leaves of different Populus species, especially Populus nigra L. (Bankova et al., 2018). CAPE is the single and most widely studied of all the individual constituents of propolis and is currently thought responsible for most of the poplar variety's strong antioxidant activity (Russo et al., 2002; Bankova et al., 2018). Besides Populus species, CAPE has been identified only in a few other botanical sources (Bankova et al., 2018). In the last few decades, much interest has been shown in exploring the biological properties of CA, CAPE, and closely related derivatives, mainly synthetic ones. These compounds are known to display antioxidant (Sud'ina et al., 1993; Russo et al., 2002), anti-inflammatory (Jung et al., 2008; Doiron et al., 2017), immunomodulatory (Natarajan et al., 1996), cytostatic (Jung et al., 2007), antibacterial (Arasoglu et al., 2016), and antiviral (Erdemli et al., 2015) properties. Besides these important activities, CA and its derivatives have shown a very high potential for treating and preventing cardiovascular diseases in preclinical studies. Their useful biological activities, coupled with favorable safety profiles, make them good candidates for clinical studies. The aim of this paper is to provide a comprehensive and up-todate review of the main cardiovascular actions attributed to CA and its derivatives both in vitro and in vivo in order to highlight their main therapeutic potentials.

\section{GENERAL CHARACTERIZATION, BIOAVAILABILITY, AND METABOLISM}

Caffeic acid [(E)-3-(3,4-dihydroxyphenyl)prop-2-enoic acid] is a white amorphous powder with a molecular mass of $180.16 \mathrm{~g} / \mathrm{mol}$. Its partition coefficient $(\log P)$ differs between publications, ranging between 1.0 and 1.3 (Wu W.M. et al., 2007; Kudugunti et al., 2010; Paracatu et al., 2014). In its free form, CA is absorbed in the gastrointestinal tract through monocarboxylic acid transporters (Konishi and Kobayashi, 2004; Konishi et al., 2004) and, to a lesser extent, through transepithelial flux (Konishi et al., 2003). Gut microbiota is also involved in the metabolism of CA. In fact, under anaerobic conditions, CA undergoes decarboxylation, which is carried out by the bacteria possessing tyrosine decarboxylase, with the corresponding product [3-(3hydroxyphenyl)-propionic acid] displaying greater antioxidant activity compared to CA (Shen et al., 2020). Once absorbed, CA undergoes extensive metabolic transformations in the liver and kidneys (Ito et al., 2005; Lafay et al., 2006; El-Seedi et al., 2012). Caffeic acid has revealed a good safety profile in a phase 1 clinical trial (NCT02050334) (Information, 2015).

Caffeic acid phenethyl ester [2-phenylethyl (E)-3-(3,4dihydroxyphenyl)prop-2-enoate] is a white crystalline solid with a molecular mass of $284.31 \mathrm{~g} / \mathrm{mol}$. It is lipophilic with $\log \mathrm{P}$ values differing between publications, ranging between 3.2 and 13.8 (Koltuksuz et al., 1999; Wu W.M. et al., 2007; Paracatu et al., 2014), which allows it to cross the blood-brain barrier in rats (Wei et al., 2004; Barros Silva et al., 2013). As the isolation and purification of CAPE from natural sources are expensive, low-yielding and time-consuming, several chemical and enzymatic synthetic methods have been developed (Bankova et al., 2018). CAPE has been shown to have very low toxicity to normal cells compared to cancer cells (Li et al., 2016). It is easily absorbed after intraperitoneal injection (Koltuksuz et al., 1999). In rat plasma, CAPE is known to remain stable for only $6 \mathrm{~h}$, after which it is metabolized and excreted mostly in urine as both a glucuronide conjugate and unmodified (Wang X. et al., 2007). Given that only a low percentage of the administered dose is recovered, CAPE is thought to be highly susceptible to hydrolysis in plasma and cell-containing esterase enzymes in rats, with CA being the resulting product (Celli et al., 2004; Tang and Sojinu, 2012). This susceptibility is not seen in vitro in human plasma, where CAPE is known to be fairly stable by forming a complex with albumin (Celli et al., 2007; Li et al., 2016). The absence of carboxylesterase in human plasma may also contribute to this stability (Celli et al., 2004; Li et al., 2016). CAPE is known to be bioactivated by tyrosinase, an enzyme that is over-expressed in melanoma cell lines, to CAPE-quinone. This compound, like CAPE itself, then reacts with glutathione (GSH) to form the CAPE-SG conjugate. Both the CAPE-SG conjugate and CAPE-quinone inhibit glutathione S-transferase (GST) (Kudugunti et al., 2011). CAPE also interacts with liver cytochrome P450 (CYP) enzymes by decreasing the activity of isoforms CYP1A1/2 and CYP2B1/2 $12 \mathrm{~h}$ after administration (Beltrán-Ramírez et al., 2008). The pharmacokinetic profile of CAPE was obtained in Sprague-Dawley rats, with a volume of distribution ranging from 1555 to $5209 \mathrm{~mL} / \mathrm{kg}$, which lowers with increasing doses. The elimination half-life ranges from 21.2 to $26.7 \mathrm{~min}$ and is dose-independent (Wang X. et al., 2009).

The high cost associated with the production of high purity CAPE, which includes using ethanol or dimethyl sulfoxide (DMSO) as solvents, is an obvious obstacle for its clinical use (Yeğin et al., 2020). Furthermore, given CAPE's instability in rat plasma and in circulation, several CA and CAPE metabolites and synthetic structural analog compounds have been investigated (see Figure 1). Caffeic acid phenethyl amide (CAPA) is a synthetic derivative that has proven more resistant to esterase hydrolysis for its amide moiety by displaying a 77 -fold increase in stability in plasma in relation to CAPE at $37^{\circ} \mathrm{C}$ (Yang J. et al., 2012). Caffeic acid phenethyl amide is less toxic to normal cells compared to CAPE, although no difference in cytoprotection has been found between the two compounds (Yang J. et al., 2010). Caffeic acid ethanolamine (CAEA) is another synthetic derivative which has, to date, been discussed in only one publication, with no mention to its chemical stability (Lee et al., 2015b). Several CAPE and CAPA fluorinated compounds have also been synthesized and their stability studied (Wang X. et al., 2006, 2007; Yang J. et al., 2010). One of these compounds, 3-(2-fluoro-4,5-dihydroxyphenyl)-acrylic acid phenethyl ester (FCAPE), appears to be more stable than CAPE (Wang X. et al., 2006, 2007), displays cytoprotective action, and its pharmacokinetic profile is also known. Its volume of distribution is $7596 \mathrm{~mL} / \mathrm{kg}$ and its elimination half-life is $31.6 \mathrm{~min}$ (Wang X. et al., 2009). Three fluorinated CAPA derivatives (FCAPA1-3) have also been found to not be toxic and display 
<smiles>Cc1ccc(CCC(C)C)cc1C</smiles>

Caffeic acid (CA)<smiles>O=CCCc1ccc(O)c(O)c1</smiles>

Dihydrocaffeic acid (DHCA)<smiles>Cc1ccc(CCC(C)CCCc2ccccc2)cc1C</smiles>

Caffeic acid phenethyl ester (CAPE)<smiles>O=C(/C=C/c1ccc(Br)c(Br)c1)OCCc1ccccc1O</smiles><smiles>CCCCC(C)CCc1ccc(C)c(C)c1</smiles><smiles>C=C(CCCc1ccccc1)CCc1ccc(C)c(C)c1</smiles>

Caffeic acid ethanolamide (CAEA)<smiles>CCCOC(=O)/C=C/c1ccc(O)c(O)c1</smiles>

Propyl caffeate<smiles>C=C(/C=C/c1ccc(F)c(F)c1)C1CCCC1</smiles>

Pyrrolidinyl caffeamide (PLCA)<smiles>O=C(/C=C/c1ccc(O)c(O)c1)OCCc1ccc(O)cc1</smiles>

para-nitro caffeic acid phenethyl ester (p-nitro-CAPE)<smiles>O=C(/C=C/c1ccc(O)c(O)c1)OCCc1ccc(O)c(O)c1</smiles>

Teucrol<smiles>O=C(/C=C/c1cc(O)c(O)c(I)c1)NCCc1ccccc1</smiles><smiles>CC(CCCc1ccccc1)CCC1CCC(C)C(C)C1</smiles>

FCAPA-3<smiles>O=C(/C=C/c1ccc(O)c(O)c1)CCC(c1ccccc1)c1ccccc1</smiles>

FCAPA-2
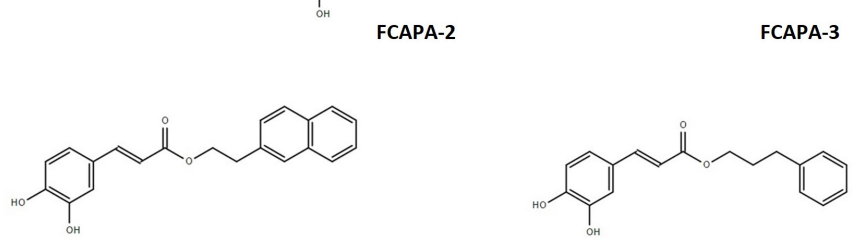

2-(2-Naphthyl)ethyl 3,4-dihydroxycinnamate

3-Phenylpropyl (2E)-3-(3,4-dihydroxyphenyl)acrylate

FIGURE 1 | Structure of caffeic acid and its derivatives. This figure was made with ChemSpider software.

cytoprotective action (Yang J. et al., 2010). Ortho- and paranitro-CAPE derivatives have also been synthetized and display cytoprotective action as well (Du et al., 2016; Li et al., 2018). Several other CA and CAPE derivatives, including alkyl esters, have been investigated, although cytoprotection and stability profiles have only been established for a small portion (Gaglione et al., 2013; Teixeira et al., 2013; Bhullar et al., 2014; Zhang P. et al., 2014; Khan et al., 2016). Only the compounds that show promising biological effects at the cardiovascular system level will be discussed in this paper.

The interest in CA and its derivatives in recent years has lied more in their antioxidant, anti-inflammatory and immunomodulatory properties, while the characterization of their cardiovascular actions has not advanced at the same speed. This paper intends to provide an up-to-date and comprehensive review of the actions of $\mathrm{CA}$ and its derivatives in the cardiovascular system, while focusing on their vasoactive actions.

\section{BIOLOGICAL ACTIVITIES ON THE CARDIOVASCULAR SYSTEM}

\section{Vasorelaxant Effect}

CA, CAPE, and CAPA all possess vasorelaxant activities by acting mainly on endothelial and vascular smooth muscle (VSM) cells through different molecular targets. Detailed results of papers published on these compounds' vasorelaxant effects are presented in Table 1. Figure 2 provides details of the currently proposed mechanisms for the vasorelaxant action of CA and its derivatives in the endothelial and VSM cells. The studies that have assessed the vascular action of these compounds have used norepinephrine (NE), phenylephrine (PE), potassium or potassium chloride $(\mathrm{KCl})$, prostaglandin $\mathrm{F}_{\alpha}\left(\mathrm{PGF}_{\alpha}\right)$ and endothelin (ET) as pre-constricting drugs in blood vessel rings that are either intact or denuded (i.e., with no endothelium). In a medium provided with calcium, $\mathrm{NE}, \mathrm{PE}, \mathrm{PGF} 2 \alpha$, and $\mathrm{ET}$ induce VSM cell contraction through the receptor-mediated activation of phospholipase $\mathrm{C}$ and inositol triphosphate/diacylglycerol pathway, which leads to calcium being released from intracellular stores (Watanabe et al., 1994; Malhotra, 1998; Cotecchia, 2010; Horinouchi et al., 2013). Potassium and $\mathrm{KCl}$-induced contraction are due to membrane depolarization, which results in calcium influx through voltage-gated channels (Godfraind et al., 1986).

\section{Caffeic Acid}

Caffeic acid shows moderate vasorelaxant activity. In PGF $2_{\alpha^{-}}$ precontracted porcine coronary arteries, CA induces the release of nitric oxide (NO) and vessel relaxation, most of which is abolished in denuded vessels or in intact vessels blocked with $\mathrm{N}^{\mathrm{G}}$-monomethyl-L-arginine (L-NMMA, nitric 
TABLE 1 | Description and main results of the studies (in vitro, ex vivo) characterizing the effect of caffeic acid and its derivatives on the vasculature (CA-caffeic acid; CAPE-caffeic acid phenethyl ester; CAPA-caffeic acid phenethyl amide; w.o.-weeks old; m.o.- months old).

\begin{tabular}{|c|c|c|c|c|c|}
\hline Authors & $\begin{array}{l}\text { Species/strain (age, } \\
\text { weight) }\end{array}$ & $\begin{array}{l}\text { Studied blood } \\
\text { vessel }\end{array}$ & Drug & Drug concentration & Effect on vasculature \\
\hline $\begin{array}{l}\text { Andriambeloson et al. } \\
\text { (1998) }\end{array}$ & $\begin{array}{l}\text { Male Wistar rats (12-14 } \\
\text { w.o.; undisclosed animal } \\
\text { weight) }\end{array}$ & Thoracic aorta & CA & $10^{-5}-3 \times 10^{-1} \mathrm{~g} / \mathrm{L}$ & $\begin{array}{l}\text { Relaxation of intact and denuded vessels } \\
\text { pre-contracted with norepinephrine }\end{array}$ \\
\hline Taubert et al. (2002) & $\begin{array}{l}\text { Female and castrated male } \\
\text { pigs ( } 7-9 \text { m.o.; undisclosed } \\
\quad \text { animal weight) }\end{array}$ & $\begin{array}{l}\text { Right coronary } \\
\text { artery }\end{array}$ & $\mathrm{CA}$ & $\begin{array}{l}\text { Concentration range not } \\
\text { disclosed }\end{array}$ & $\begin{array}{c}\text { Relaxation of intact vessels pre-contracted with } \\
\text { PGF2 } 2_{\alpha} \text {, abolished by endothelium removal and by } \\
\text { L-NMMA (from } \mathrm{pD}_{2} \text { values published in this paper, } \\
\text { a concentration of } 0.01 \mu \mathrm{M} \text { is inferred to have been } \\
\text { used) }\end{array}$ \\
\hline \multirow[t]{2}{*}{ Cicala et al. (2003) } & $\begin{array}{c}\text { Male Wistar rats } \\
\text { (200-250 g; undisclosed } \\
\text { age) }\end{array}$ & Thoracic aorta & CAPE & $0.1-300 \mu \mathrm{M}$ & $\begin{array}{l}\text { Concentration-dependent inhibition of } \\
\text { phenylephrine-induced contraction }\end{array}$ \\
\hline & & & & & $\begin{array}{c}\text { Inhibition of } \mathrm{KCl} \text {-induced contraction at high } \\
\text { concentration (inhibition of intracellular calcium } \\
\text { increase) }\end{array}$ \\
\hline Long et al. (2009) & $\begin{array}{l}\text { Pig (undisclosed animal age } \\
\text { and weight) }\end{array}$ & $\begin{array}{l}\text { Left anterior } \\
\text { descending } \\
\text { coronary artery }\end{array}$ & CAPE & CAPE 1-1000 $\mu \mathrm{M}$ & $\begin{array}{l}\text { Relaxation of vessels pre-contracted with } \mathrm{KCl} \text { or } \\
\text { PGF } 2_{\alpha} \text {. Relaxation was abolished by propranolol, } \\
\text { methylene blue, L-NNA and SQ22536, but not by } \\
\text { indomethacine }\end{array}$ \\
\hline Çeçen et al. (2016) & $\begin{array}{l}\text { Female Wistar-Albino rats } \\
\text { (250-300 g; undisclosed } \\
\text { age) }\end{array}$ & Thoracic aorta & CAPE & $10,100,300 \mu \mathrm{M}$ & $\begin{array}{l}\text { Concentration-dependent inhibition of } \\
\text { phenylephrine-induced contraction }\end{array}$ \\
\hline Duman et al. (2014) & $\begin{array}{l}\text { Human subjects } \\
\text { (undisclosed data) }\end{array}$ & $\begin{array}{l}\text { Umbilical } \\
\text { arteries }\end{array}$ & CAPE & $0.1-1000 \mu \mathrm{M}$ & $\begin{array}{l}\text { Relaxation of arteries pre-constricted with } \\
\text { endothelin and PGF2 } \alpha\end{array}$ \\
\hline \multirow[t]{3}{*}{ Ho et al. (2013) } & $\begin{array}{l}\text { Healthy and } \\
\text { streptozotocin-induced } \\
\text { diabetic male Wistar rats (8 } \\
\text { w.o.; 250-300 g) }\end{array}$ & $\begin{array}{l}\text { Coronary } \\
\text { arteries }\end{array}$ & CAPA & $\begin{array}{l}1,3 \text {, and } 10 \mu \mathrm{M} \\
\text { administered intravenously } \\
\text { to isolated hearts }\end{array}$ & $\begin{array}{c}\text { Concentration-dependent increase in coronary } \\
\text { blood flow in healthy and diabetic rats, although } \\
\text { less pronounced in the latter }\end{array}$ \\
\hline & & Thoracic aorta & & $\begin{array}{l}3 \mathrm{mg} / \mathrm{kg} \text { CAPA } \\
\text { administered } \\
\text { intraperitoneally twice daily } \\
\text { for } 4 \text { weeks }\end{array}$ & $\begin{array}{l}\text { Concentration-dependent relaxation of } \\
\text { endothelium-intact and endothelium-denuded } \\
\text { aortae pre-constricted with phenylephrine. }\end{array}$ \\
\hline & & & & & $\begin{array}{l}\text { A right shift in the dose-response of } \\
\text { phenylephrine-induced contraction. The effect was } \\
\text { more pronounced in intact vessels. }\end{array}$ \\
\hline
\end{tabular}

oxide synthase (NOS) blocker), which suggests the importance of the endothelial NO-cyclic guanosine monophosphate (cGMP) pathway (Taubert et al., 2002). Conversely, in rat thoracic aortae pre-contracted with $\mathrm{NE}$, there is no difference in the CAinduced relaxation between intact and denuded vessels, which indicates that this effect is endothelium-independent in this vessel (Andriambeloson et al., 1998). Therefore, the vasorelaxant activity of CA seems site-specific.

\section{Caffeic Acid Phenethyl Ester}

Of all the CA derivatives, CAPE is the single most widely studied compound for its vasorelaxant action. Studies on rat thoracic aortae have established that CAPE induces vasorelaxation through both an endothelium-dependent mechanism, which occurs with low concentrations, and an endothelium-independent mechanism occurring with high concentrations (Cicala et al., 2003; Çeçen et al., 2016).

\section{Endothelium-dependent mechanism}

Caffeic acid phenethyl ester causes the concentration-dependent relaxation of different types of intact vessels pre-contracted with PE (Cicala et al., 2003), ET (Duman et al., 2014), or PGF $2_{\alpha}$ (Duman et al., 2014), but not with $\mathrm{KCl}$ (Cicala et al., 2003; Long et al., 2009). Addition of $\mathrm{N}^{\mathrm{G}}$-nitroarginine methyl ester (L-NAME, NOS inhibitor) to intact rat thoracic aortae pre-contracted with $\mathrm{PE}$ abolishes the vasorelaxant effect of CAPE at low concentrations (0.1-100 $\mu \mathrm{M})$, with the same response being observed in endothelium denuded vessels (Cicala et al., 2003). Similarly, addition of L-NAME to human umbilical arteries pre-contracted with $\mathrm{PGF} 2_{\alpha}$ or ET also inhibits vasorelaxation (Duman et al., 2014). In porcine coronary arteries, vasorelaxation is partially abolished by $\mathrm{N}^{\omega}$ nitro-L-arginine (L-NNA, NO synthase (NOS) inhibitor) and methylene blue (soluble guanyl cyclase inhibitor) (Long et al., 2009). These results strongly suggest that CAPE-mediated vasodilation is due to an increase in the endothelial NO-cGMP pathway, probably by enhancing the activity of endothelial NOS (eNOS). Furthermore, in human umbilical vein endothelial cells (HUVECs), CAPE $(1-100 \mu \mathrm{M})$ increases intracellular NO content, an effect that is concentration-dependent. However, as the highest studied concentration $(100 \mu \mathrm{M})$ actually decreases NO content with time, this suggests that impairment in 


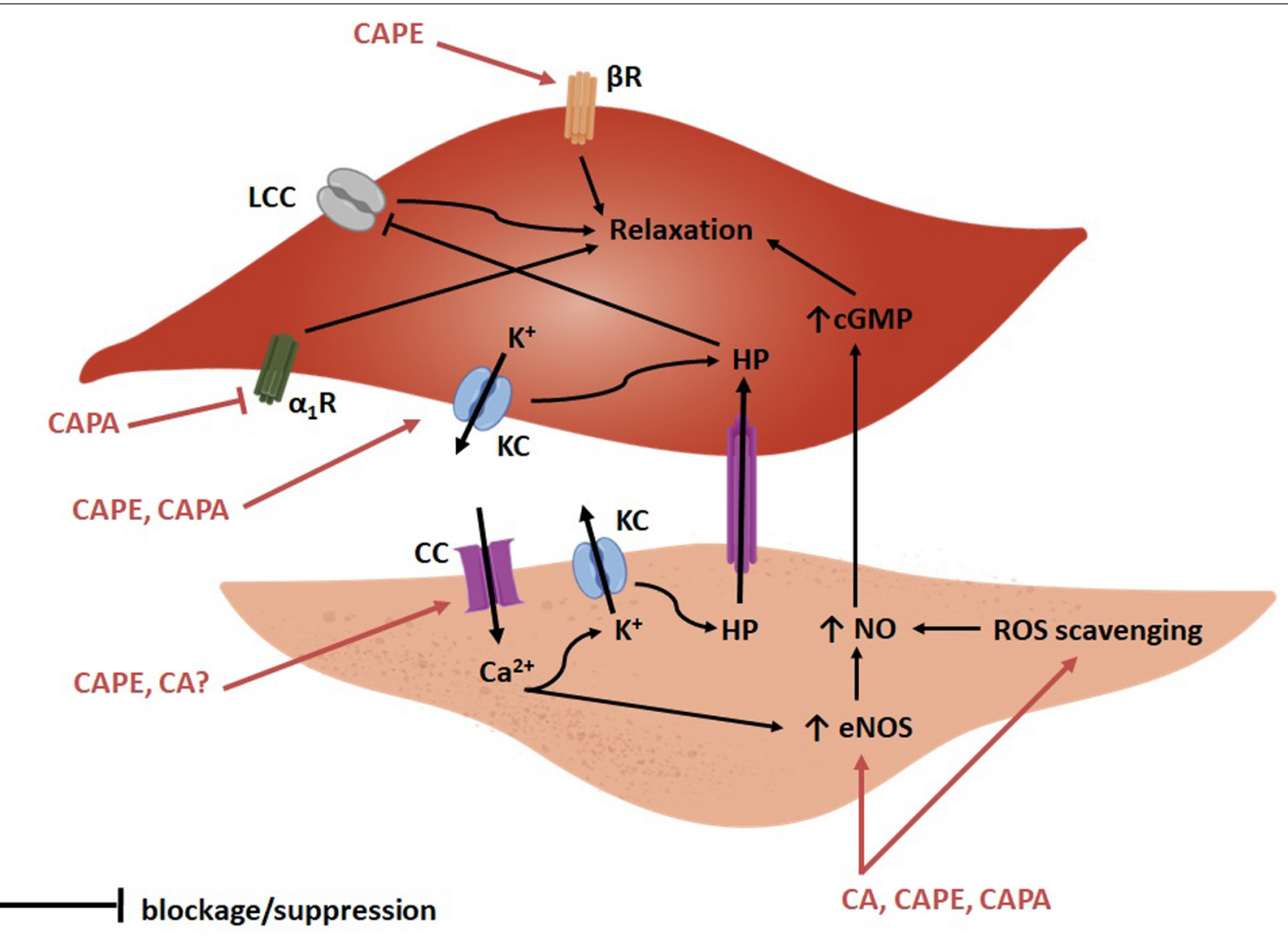

FIGURE 2 | Scheme of the proposed vasorelaxant actions of CA, CAPE and CAPA according to current research. On VSM cells (top) CAPE and CAPA may act on potassium channels (KC), which would lead to potassium efflux and hyperpolarization (HP). Hyperpolarization would contribute to inactivate L-type calcium channels (LCC) and to prevent VSM cell contraction. Additionally, CAPE may activate the beta adrenergic receptor ( $\beta$ R) and contribute to VSM cell relaxation. Additionally, CAPA may exert a weak alpha-1 receptor $\left(\alpha_{1} R\right.$ ) blocking effect. On endothelial cells (bottom), CA and CAPE may act on calcium channels (CC) and lead to calcium influx which, in turn, would open potassium channels $(\mathrm{KC})$ and lead to HP. Hyperpolarization could be communicated to VSM cells via gap junctions and reinforce its relaxation. Calcium may also increase endothelial nitric oxide synthase (eNOS) activity and increase NO synthesis, which would diffuse into and relax VSM cells. In addition, CA, CAPE, and CAPA may also scavenge reactive oxygen species (ROS) and prevent NO removal therefore increasing its cellular content.

endothelial cell viability may occur with CAPE at high concentrations (Kamil Burgazli et al., 2013). Furthermore, the endothelial secretion of vasodilator prostaglandins does not seem to be involved in CAPE-mediated vasorelaxation as indomethacin [cyclooxygenase (COX) inhibitor] does not affect the relaxation of porcine coronary arteries (Long et al., 2009).

\section{Endothelium-independent mechanism - role of calcium channels}

In both intact and denuded $\mathrm{KCl}$-precontracted rat thoracic aortae, the vasorelaxant effect of CAPE is evident only at the highest studied concentration $(100 \mu \mathrm{M})$, which suggests the existence of an endothelium-independent relaxation mechanism (Cicala et al., 2003). In fact, at high concentrations, CAPE also inhibits PE-triggered contraction in a calcium-free medium, suggesting that it prevents either the mobilization of calcium from intracellular stores or its influx across the VSM cell membrane (Cicala et al., 2003; Çeçen et al., 2016). In porcine coronary arteries, CAPE inhibits both $\mathrm{KCl}$ concentrationdependent contraction, but also reduces the calcium concentration-dependent contraction in a potassium-rich medium (Long et al., 2009). These results reveal CAPE's calciumantagonistic property and suggest that CAPE could inhibit calcium influx through voltage-gated channels in VSM cells.

\section{Endothelium-independent mechanism - role of potassium channels}

When propranolol (beta adrenergic receptor blocker) and $\mathrm{N}$-nitro-L-arginine (L-NNA) are applied together to porcine coronary arteries, CAPE is still able to induce relaxation, which suggests the existence of yet another vasorelaxant mechanism. A possibility that is currently being considered is that CAPE acts on VSM potassium channels as their activation will lead to hyperpolarization and, consequently, to diminished activity of voltage-gated L-type calcium channels and vasorelaxation. This hypothesis has been proposed as CAPE is already known to stimulate the large conductance calcium-activated potassium channels $\left(\mathrm{BK}_{\mathrm{Ca}}\right)$ in rat pituitary $\mathrm{GH} 3$ cells (Lin et al., 2004) and human oral keratinocytes (Shieh et al., 2005). Although the potential of CAPE to modulate vascular $\mathrm{BK}_{\mathrm{Ca}}$ channels still needs to be explored, there is evidence to suggest that it effectively contributes to the modulation of potassium channels in 
endothelial cells. Stimulating HUVECs with CAPE $(1-100 \mu \mathrm{M})$ leads to a concentration-dependent increase in the cytosolic calcium concentration and, consequently, to hyperpolarization evoked by calcium-activated potassium channels. However, the latter has been observed only for the 10 and $100 \mu \mathrm{M}$ concentrations (Kamil Burgazli et al., 2013). A rise in cytosolic calcium would lead to NO secretion which, downstream in its signaling pathway, would lead to VSM cell membrane hyperpolarization and to diminished calcium influx.

\section{Role of beta receptors in vasorelaxation}

Another mechanism for the vasorelaxant effect of CAPE seems to involve vascular beta adrenergic receptors. Alpha and beta adrenergic receptors are present in both endothelial and VSM cells (Sorriento et al., 2011). Stimulation of beta adrenergic receptors results in vasorelaxation through the activation of adenylate cyclase in VSM cells (Kuriyama et al., 1982) and of NOS in endothelial cells. There are opposing results about the role of adenylate cyclase in the vasorelaxation by CAPE. In intact porcine coronary arteries, propranolol (beta blocker) and SQ22536 (adenylate cyclase inhibitor) reduce CAPE-induced vasorelaxation, which suggests that the activation of beta receptors and cyclic adenosine monophosphate (cAMP) may be involved in this responde (Long et al., 2009). This assertion is logical given the partial structural homology that CAPE shares with the catechol ring of catecholamines, which could justify its action on adrenergic receptors (Cicala et al., 2003; Long et al., 2009). In contrast, in denuded rat aortae, CAPE-mediated relaxation is not affected by inhibition of adenylate cyclase (Cicala et al., 2003). This would suggest that CAPE's action on beta receptors is more pronounced in endothelial cells rather than VSM cells, or CAPE's action on endothelial cells might inhibit VSM cell contraction. This latter hypothesis is reasonable as the increase in intracellular cGMP (evoked by NO) and cAMP (evoked by beta receptor stimulation) inhibits calcium channels in VSM cell membranes (Ishikawa et al., 1993; Kelly et al., 2007).

\section{Caffeic Acid Phenethyl Amide}

Caffeic acid phenethyl amide also exhibits vasorelaxant action. In rat coronary arteries from isolated hearts, CAPA $(1-10 \mu \mathrm{M})$ increases blood flow, which is partially abolished with L-NAME. This suggests that CAPA activates the endothelial NO-cGMP pathway (Ho et al., 2013), which has been attributed to CAPA's radical scavenging activity that prevents $\mathrm{NO}$ degradation by reactive oxygen species (ROS). Although there are no studies that have yet tested this hypothesis, it has been proposed that CAPA can also increase manganese superoxide dismutase activity in the vasculature (Ho et al., 2013), similarly to its known effect on adipose tissue (Weng et al., 2012). Conversely, in intact and denuded rat thoracic aortae, CAPA $(1,3,10,30,100$, and $300 \mu \mathrm{M})$ shows concentration-dependent inhibition of potassium or PEmediated constriction. In intact vessels this relaxation is not inhibited by L-NAME (NOS blocker), ODQ (NO-sensitive guanylate cyclase blocker) or methylene blue (soluble guanylate cyclase blocker). Endothelium removal exerts no difference in CAPA-mediated relaxation in PE-constricted vessels, but decreases the relaxation of potassium-constricted vessels. The same study has shown that CAPA also acts as a weak alphaadrenergic receptor blocker (Ho et al., 2013). Taken together, these results apparently indicate that the molecular target of $\mathrm{PE}$ (alpha adrenergic receptor) is present in endothelial and VSM cells, whereas the target of potassium-induced contraction (voltage-gated calcium channel) seems more prevalent in VSM cells. Given the structural analogy to CAPE, in addition to its alpha adrenergic blocker activity, CAPA may also act as a potassium channel activator.

There is a notable shortage of studies that focus on exploring the effects of CA and its derivatives on perfusion in vivo. The few articles to have assessed perfusion in vivo have compared CAPE pre-treated and untreated animals subjected to ischemiareperfusion injuries by using laser Doppler flowmetry as a technique to confirm ischemia during surgery (Zhou et al., 2006; Khan et al., 2007). To the authors' knowledge, there are no ongoing clinical trials that employ CA or its derivatives for therapeutic intentions with cardiovascular diseases.

\section{Inhibitory Activity on the Renin-Angiotensin-Aldosterone Axis}

Caffeic acid and several derivatives are known to modulate the renin-angiotensin-aldosterone endocrine axis in vitro (Bhullar et al., 2014). Caffeic acid phenethyl ester shows a higher renin inhibitory activity over CA, whereas CAPA shows weak activity. The derivative with the highest renin inhibition was a caffeic acid diphenylethyl ester [2,2Diphenylethyl (2E)-3-(3,4-dihydroxyphenyl)acrylate], followed by a caffeic acid naphthylethyl ester [2-(2-Naphthyl)ethyl 3,4-dihydroxycinnamate]. Regarding the ability to inhibit angiotensin converting enzyme (ACE), CA, CAPE and the phenylpropyl ester of caffeic acid [3-Phenylpropyl (2E)-3-(3,4dihydroxyphenyl)acrylate] show a strong activity. Caffeic acid phenethyl ester also shows an inhibitory activity and higher than CAPA. Most of these compounds showed weak inhibition activity against aldosterone. Caffeic acid phenethyl ester was the weakest compound, while CA, CAPA and the CA derivative propyl caffeate showed higher activities. Although these results derive from an in vitro study, they have been demonstrated recently in cyclosporine-induced hypertensive Sprague-Dawley rats, where CA significantly lowered plasma ACE activity (Agunloye et al., 2019). Further research is needed to assess whether other CA derivatives share these activities in vivo and whether they contribute significantly to blood pressure regulation.

\section{Effect on Heart Rate and Blood Pressure}

To the authors' knowledge, to the present date there are no published studies exploring the effect of administering CA or its derivatives on cardiovascular variables (i.e., blood pressure, heart rate) in humans. The only available studies have assessed the impact of consuming hydroxycinnamic-rich foods on biochemical and physiological variables, including blood pressure. Although most studies suggest that a high dietary intake of hydroxycinnamic-rich foods confers protection against cardiovascular disease, especially in high risk patients, it cannot be inferred that this benefit is attributed solely to CA, CAPE 
or any other derivative (Martini et al., 2019). The effects of CA and its derivatives on cardiovascular variables assessed in vivo in preclinical studies are detailed in Table 2.

\section{Caffeic Acid}

Caffeic acid administered intravenously at $10 \mathrm{mg} / \mathrm{kg}$ to healthy female Wistar rats under pentobarbital anesthesia lowers blood pressure and heart rate (Leeya et al., 2010). However, doses of $10 \mathrm{or} 50 \mathrm{mg} / \mathrm{kg}$ delivered intraperitoneally are unable to lower blood pressure in rats undergoing cerebral artery occlusion under chloral hydrate anesthesia (Zhou et al., 2006). Given CA's lipophilic character, it is improbable that this difference in response should be attributed to the administration route. It could be rather attributed to differences in vascular and/or autonomic reactivity to the employed anesthetic schemes. However, a similar lack of hypotensive effect is observed when $\mathrm{CA}$ is administered orally to conscious rats with adenine-induced renal failure and cyclosporine-induced hypertension. When administered orally at a $10 \mathrm{mg} / \mathrm{kg} /$ day dose for 24 days to rats with renal failure (and hypertension), CA fails do decrease blood pressure (Yokozawa et al., 1995). When administered orally at doses of 10 and $15 \mathrm{mg} / \mathrm{kg} /$ day for 7 days to cyclosporine-induced hypertensive rats, CA decreases systolic blood pressure and heart rate. In this study, plasma ACE and heart acetylcholinesterase and butyrylcholinesterase activities were decreased, as well as plasma and heart arginase activities (Agunloye et al., 2019). From these results, it can be inferred that CA increased the effect of acetylcholine on the heart and decreased plasma angiotensin II levels, thus probably having decreased blood pressure through modulation of the cardiac output and peripheral vascular resistance. Therefore, when considering the oral administration route, present data suggests that treatment duration is a major determinant of CA's hypotensive effect. Nevertheless, it is also probable that the oxidative stress underlying the pathophysiology in these animal models might oppose CA's hypotensive effect.

\section{Caffeic Acid Phenethyl Ester}

Caffeic acid phenethyl ester administered intravenously to Sprague-Dawley rats lowers heart rate and mean blood pressure levels in a dose-dependent manner (Iraz et al., 2005a). A dose of $1 \mathrm{mg} / \mathrm{kg}$ lowers blood pressure for up to $20 \mathrm{~s}$, whereas the effect lasts up to $2 \mathrm{~min}$ at 5 and $10 \mathrm{mg} / \mathrm{kg}$. A dose of $20 \mathrm{mg} / \mathrm{kg}$ causes death within seconds, probably due to hemodynamic shock caused by severe hypotension and bradycardia (Iraz et al., 2005a). In rats subjected to bilateral vagotomy or receiving atropine, the negative chronotrope effect of CAPE at a dose of $5 \mathrm{mg} / \mathrm{kg}$ is suppressed, suggesting that CAPE stimulates the parasympathetic nervous system on the heart (Iraz et al., 2005b).

Caffeic acid phenethyl ester has shown the ability to stimulate beta adrenergic receptors in VSM cells as well as to potentiate the release of NO from the vascular endothelium. Given that there are no studies investigating whether CAPE exerts similar actions on cardiomyocytes, current evidence suggests that it solely modulates cardiac parasympathetic activity. Given that neither vagotomy nor atropine prevent CAPE's hypotensive effect (Iraz et al., 2005b), the latter must be attributed to its vasorelaxant effect. It can, thus, be assumed that CAPE-mediated vasorelaxation is potent enough, together with its bradycardic effect, to lower blood pressure. These studies report a minor difference in the duration of the blood pressure lowering effects of CAPE. In the first study (Iraz et al., 2005a), CAPE lowered blood pressure for up to $2 \mathrm{~min}$, which went down to $1 \mathrm{~min}$ in the second study (Iraz et al., 2005b). As equal experimental conditions were used in both studies, this difference in effect could be attributed to the difference in sample size at least.

Oral CAPE administration seems to lose potency versus intravenous and intraperitoneal administrations, at least in healthy animals. A dose of $30 \mathrm{mg} / \mathrm{kg} /$ day administered by oral gavage for 6 weeks did not significantly change the blood pressure of healthy Wistar rats (Hassan et al., 2014). As an intravenous dose of $20 \mathrm{mg} / \mathrm{kg}$ was certain to lower both heart rate and blood pressure of healthy Sprague-Dawley rats (Iraz et al., 2005a), the lack of a measurable response in this case should be primarily attributed to the administration route, although strain-specific pharmacokinetics may also be considered. Under these conditions, the intestinal and hepatic first pass effects are apparently responsible for diminishing CAPE bioavailability and, consequently, the dose that reaches the bloodstream. Still, insulin-resistant and insulin-deficient rats benefit from oral CAPE administration $(30 \mathrm{mg} / \mathrm{kg} /$ day $)$ as it ameliorates the rise in blood pressure, an effect attributed to CAPE-mediated improvement of vascular reactivity and stiffness (Hassan et al., 2014). This beneficial effect was not observed in healthy controls, suggesting that orally administered CAPE may exert a higher impact in animals with a higher vascular tone, a hallmark of insulin resistance and insulin deficiency (El-Bassossy et al., 2012). In high fructose consumer diabetic rats, subacute CAPE administrations ( $50 \mu \mathrm{mol} / \mathrm{kg} / \mathrm{day}$ intraperitoneally for 2 weeks) ameliorate the rise in blood pressure that accompanies this metabolically mediated vascular damage, and was attributed to increased eNOS levels, even though an anti-inflammatory effect cannot be ruled out (Gun et al., 2016). Furthermore, as CAPE is also able to reduce insulin resistance (Hassan et al., 2014), it can be argued that this blood pressure-lowering effect might also be attributed to increased vasculature sensitivity to insulin's vasorelaxant action.

Blood pressure has been monitored in several studies of ischemia/reperfusion (I/R) injuries, and CAPE's vasorelaxant activity has been assessed. In the vast majority of these studies, CAPE failed to lower blood pressure in comparison to control groups. Given that different experimental conditions were involved, including administration routes, CAPE doses, and anesthetic schemes, these factors seem to be the primary causes for the apparent lack of blood pressure response. In studies into coronary artery $\mathrm{I} / \mathrm{R}$, at first glance the CAPE dose would seem to explain lack of response. When low doses are used (1-10 $\mu \mathrm{M} / \mathrm{kg}$ ), no effect is observed (Cagli et al., 2005; Ozer et al., 2005b; Parlakpinar et al., 2005), whereas with a higher dose $(50 \mu \mathrm{M} / \mathrm{kg})$ an amelioration of increased blood pressure takes place (Eşrefoglu et al., 2005). Surprisingly, in a different study with practically identical experimental conditions, the same high dose failed to produce a beneficial effect on blood pressure (Parlakpinar et al., 2005), which might justify the need to improve this experimental model in terms of reproducibility. 


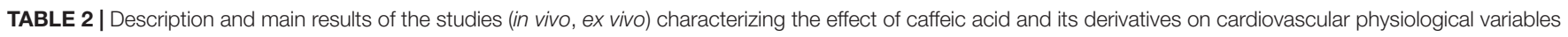
(CA-caffeic acid; CAPE-caffeic acid phenethyl ester; CAPA-caffeic acid phenethyl amide; w.o.-weeks old; CAO-coronary artery occlusion; MCAO-middle cerebral artery occlusion).

\begin{tabular}{|c|c|c|c|c|}
\hline Authors & $\begin{array}{c}\text { Species/strain (sample size, age, weight), } \\
\text { experimental procedure and anesthetic } \\
\text { scheme }\end{array}$ & Drug & $\begin{array}{c}\text { Drug dose and administration } \\
\text { route }\end{array}$ & $\begin{array}{c}\text { Effect on cardiovascular } \\
\text { physiological variables }\end{array}$ \\
\hline
\end{tabular}

Leeya et al. (2010) Healthy adult female Wistar rats $(N=6,210-250 \mathrm{~g})$

Zhou et al. (2006) under pentobarbital anesthesia

Adult male Wistar rats $(N=6,210-250 \mathrm{~g})$ subjected to middle cerebral artery occlusion (MCAO) under chloral hydrate anesthesia

Yokozawa et al. (1995)

Agunloye et al. (2019)

Iraz et al. (2005a)

Iraz et al. (2005b)

Hassan et al. (2014)

Gun et al. (2016)

Eşrefoglu et al. (2005)

Cagli et al. (2005)

Ozer et al. (2004)

Parlakpinar et al. (2005)

Male Wistar rats ( $N=8$; 10-12 w.o.; 200-250 g) subjected to CAO under urethane anesthesia

Altuğ et al. (2008)

Khan et al. (2007)

Male Wistar rats $(N=6 ; 200-210 \mathrm{~g})$ with adenine-induced renal failure and consequent hypertension (no anesthesia)

Cyclosporine-induced hypertensive rats $(N=6$, undisclosed strain, gender, age and weight; no anesthesia)

Healthy male Sprague-Dawley rats ( $N=6$; 12 w.o.; 250-300 g) under urethane anesthesia

Healthy $(N=8)$ and bivagotomized $(N=8)$ male Sprague Dawley rats (12 w.o.; 250-300 g) under urethane anesthesia

Healthy, insulin-resistant and insulin-resistant male Wistar rats ( $N=8$; 85-155 g; undisclosed age) without anesthesia

High fructose consumer Sprague Dawley rats (8 w.o.; undisclosed gender and weight) without anesthesia

Male Wistar rats ( $N=8$; 250-350 g; undisclosed age) subjected to $\mathrm{CAO}$ under urethane anesthesia

Male Wistar rats (250-350 g, undisclosed age and sample size) subjected to CAO under thiopental anesthesia

Male Wistar rats $(N=7 ; 250-350 \mathrm{~g})$ subjected to CAO under urethane anesthesia

New Zealand white male rabbits $(N=6 ; 2.5-3 \mathrm{~kg})$ subjected to MCAO under ketamine, xylazine and atropine anesthesia

Male Sprague-Dawley rats (240-260 g; undisclosed age and sample size) subjected to MCAO under xylazine-ketamine anesthesia
CAPE

$50 \mu \mathrm{mol} / \mathrm{kg} /$ day administered intraperitoneally for 2 weeks

CAPE

$50 \mu \mathrm{mol} / \mathrm{kg}$ administered intravenously $10 \mathrm{~min}$ before and during occlusion

CAPE

$10 \mu \mathrm{mol} / \mathrm{kg}$ administered intravenously 10 min before occlusion

CAPE

$1.25 \mu \mathrm{M} / \mathrm{kg} / \mathrm{min}$ administered intravenously 10 min before and during occlusion by infusion

$50 \mu \mathrm{mol} / \mathrm{kg}$ administered intravenously before and during occlusion

CAPE

Mean blood pressure and heart rate decreased only at a $10 \mathrm{mg} / \mathrm{kg}$ dose No difference in blood pressure and cerebral blood flow among sham, ischemic and ischemic $+\mathrm{CA}$ groups

No difference in systolic and mean blood pressure

Significant decrease in systolic blood pressure and heart rate

Dose-dependent decrease in mean blood pressure and heart rate;

$1 \mathrm{mg} / \mathrm{kg}$ lowered the mean blood pressure up to $20 \mathrm{~s}$ and 5 and $10 \mathrm{mg} / \mathrm{kg}$ up to $2 \mathrm{~min} ; 10 \mathrm{mg} / \mathrm{kg}$ decreased heart rate up to $10 \mathrm{~min}$; $20 \mathrm{mg} / \mathrm{kg}$ caused death after a few seconds

The mean blood pressure was lowered up to $1 \mathrm{~min}$

In healthy animals, systolic, diastolic and pulse blood pressure did not change

In insulin-resistant and insulin-deficient animals, CAPE alleviated the increase in systolic, diastolic and pulse blood pressure CAPE significantly ameliorated the increase in blood pressure that accompanied vascular damage CAPE prevented the drop in blood pressure induced by l/R injury and accelerated recovery to pre-injury values

No differences in heart rate between the control and

CAPE-treated groups

No changes in blood pressure and heart rate between the control and CAPE-treated animals No difference in heart rate or blood pressure in the control, ischemic or

CAPE-treated groups. CAPE exerted no effect during ischemia or reperfusion

No differences in blood pressure in CAPE-treated and control groups

CAPE $\quad 1,2,5$, and $10 \mathrm{mg} / \mathrm{kg}$ administered intravenously during MCAO or after reperfusion
No difference in blood pressure and heart rate between the control and animals treated with CAPE during cerebral I/R injury

Cerebral blood flow increased significantly at a dose of $2 \mathrm{mg} / \mathrm{kg}$ in comparison to controls 
TABLE 2 | Continued

\begin{tabular}{|c|c|c|c|c|}
\hline Authors & $\begin{array}{c}\text { Species/strain (sample size, age, weight), } \\
\text { experimental procedure and anesthetic } \\
\text { scheme }\end{array}$ & Drug & $\begin{array}{l}\text { Drug dose and administration } \\
\text { route }\end{array}$ & $\begin{array}{l}\text { Effect on cardiovascular } \\
\text { physiological variables }\end{array}$ \\
\hline Tsai et al. (2006) & $\begin{array}{l}\text { Male Long-Evans rats }(270-350 \mathrm{~g}) \text { subjected to } \\
\text { MCAO under halothane anesthesia }\end{array}$ & CAPE & $\begin{array}{c}0.01,0.1,1, \text { or } 10 \mu \mathrm{g} / \mathrm{kg} \\
\text { administered intravenously } 15 \mathrm{~min} \\
\text { before MCAO }\end{array}$ & $\begin{array}{l}\text { No significant changes in heart rate } \\
\text { or blood pressure between groups }\end{array}$ \\
\hline Fadillioglu et al. (2004) & $\begin{array}{l}\text { Male Sprague-Dawley rats (60 days old) receiving } \\
\text { doxorubicin under urethane anesthesia }\end{array}$ & CAPE & $\begin{array}{l}10 \mu \mathrm{mol} / \mathrm{kg} / \text { day administered } \\
\text { intraperitoneally for } 12 \text { days }\end{array}$ & $\begin{array}{l}\text { CAPE attenuated the } \\
\text { doxorubicin-induced increase in } \\
\text { heart rate and blood pressure }\end{array}$ \\
\hline Mollaoglu et al. (2006) & $\begin{array}{l}\text { Adult males Wistar Albino rats ( } N=12 ; 8 \text { w.o., } \\
280 \text { g) receiving cadmium chloride i.p., for } 15 \text { days } \\
\text { (undisclosed use of anesthesia) }\end{array}$ & CAPE & $\begin{array}{l}10 \mu \mathrm{mol} / \mathrm{kg} / \text { day administered } \\
\text { intraperitoneally for } 15 \text { days }\end{array}$ & $\begin{array}{l}\text { No significant changes in heart rate } \\
\text { or blood pressure }\end{array}$ \\
\hline Castellano et al. (2016) & $\begin{array}{c}\text { Male Sprague Dawley rats (275-325 g; undisclosed } \\
\text { age and sample size) }\end{array}$ & CAPE & $40 \mu \mathrm{M}$ & $\begin{array}{c}\text { In heart preparations CAPE } \\
\text { restored L-NAME-induced } \\
\text { compromise in left ventricle } \\
\text { diastolic and end-systolic pressures } \\
\text { after I/R injury }\end{array}$ \\
\hline \multirow[t]{3}{*}{ Chang et al. (2013) } & $\begin{array}{l}\text { Adult male Hartley guinea-pigs (300-350 g, } \\
\qquad N=9-10 ; \text { undisclosed age) }\end{array}$ & CAPE & $\begin{array}{l}1,3 \text {, and } 10 \mu \mathrm{M} \text { for cardiac } \\
\text { electrical conduction studies }\end{array}$ & $\begin{array}{l}\text { Negative chronotropic effect and } \\
\text { frequency-dependent depression of } \\
\text { AV nodal conduction. }\end{array}$ \\
\hline & & & & $\begin{array}{l}\text { Reduction in the occurrence of } \\
\text { reperfusion-induced ventricular } \\
\text { fibrillation }\end{array}$ \\
\hline & & & $\begin{array}{l}3,10,30,100 \mu \mathrm{M} \text { for cardiac } \\
\text { contraction studies }\end{array}$ & Decrease in left ventricular pressure \\
\hline \multirow[t]{2}{*}{ Ho et al. (2013) } & $\begin{array}{c}\text { Healthy }(N=5) \text { and diabetic }(N=9) \text { male Wistar } \\
\text { rats }(8 \text { w.o.; } 250-300 \text { g), under sodium } \\
\text { pentobarbital anesthesia }\end{array}$ & CAPA & $\begin{array}{l}\text { 1, 3, and } 10 \mu \mathrm{M} \text { intravenously in } \\
\text { heart preparations }\end{array}$ & No change in heart rate \\
\hline & & CAPA & $\begin{array}{c}1,5 \text {, and } 10 \mathrm{mg} / \mathrm{kg} \text { administered } \\
\text { orally by gavage }\end{array}$ & $\begin{array}{c}\text { No changes in blood pressure (data } \\
\text { not shown in paper) }\end{array}$ \\
\hline
\end{tabular}

At lower doses, it can also be argued that I/R-mediated oxidative stress suffices to offset CAPE's vasorelaxant and blood pressurelowering action. This has, once again, been observed in middle cerebral artery I/R studies, where low concentrations failed to have a beneficial effect on blood pressure (Tsai et al., 2006; Khan et al., 2007; Altuğ et al., 2008).

Blood pressure and heart rate have also been monitored in toxicity studies. In Sprague-Dawley rats, $10 \mu \mathrm{mol} / \mathrm{kg} /$ day for a 12-day pretreatment with CAPE administered intraperitoneally attenuated the doxorubicin-mediated increase in heart rate and blood pressure (Fadillioglu et al., 2004). In contrast, the same dose administered intraperitoneally for 15 days to Wistar rats did not significantly ameliorate the cadmium-induced increase in blood pressure despite its beneficial effects on myocardial and vascular histology (Mollaoglu et al., 2006). In this case, the differences in animal strain, treatment duration and general mechanism of lesion can be attributed to these seemingly opposing results. Finally, it has been proposed that CAPE might not produce significant changes in blood pressure due to opposing actions on primary blood pressure determinants. On the one hand, CAPE may have a positive inotropic agent (induction of beta adrenergic receptor by NO) and promote coronary vasodilation by increasing cardiac output; on the other hand it may decrease peripheral resistance by its vasorelaxant effect. In this way, the mean blood pressure might remain stable (Ilhan et al., 2014). For this reason, the effect of CAPE and other CA derivatives on hemodynamics should be clarified in vivo by simultaneously assessing perfusion and blood pressure.

Caffeic acid phenethyl ester has also demonstrated an antiarrhythmic effect on an animal model of myocardial infarction, which has not attributed to direct action in cardiomyocytes, but to indirect actions via ROS scavenging, and possibly vasorelaxant effects (Huang et al., 2005). In isolated guinea pig hearts, CAPE displays a negative chronotropic effect and frequency-dependent depression of atrioventricular nodal conduction. CAPE also exhibits an antiarrhythmic effect by reducing the occurrence of reperfusion-induced ventricular fibrillation and decreased left ventricular pressure. These effects are not attributed to CAPE's antioxidant or anti-inflammatory effects, rather to its ability to interact with cardiomyocyte ion channels. Although CAPE also acts on potassium channels (slight inhibition of delayed outward channels, with no effect on inward rectifier channels), these effects are attributed to the inhibition of inward sodium and calcium currents (Chang et al., 2013).

\section{Caffeic Acid Phenethyl Amide}

Caffeic acid phenethyl amide administered orally by gavage ( 1,5 , and $10 \mathrm{mg} / \mathrm{kg}$ ) does not change blood pressure in Wistar rats, but a weak alpha-adrenergic receptor blocking effect is recognized. When administered to heart preparations, concentrations of 1, 3, and $10 \mu \mathrm{M}$ do not significantly lower heart rate, which suggests 
that, as with CAPE, the central nervous system may be required for CAPA's possible bradycardic effect (Ho et al., 2013).

\section{Anti-inflammatory and Immunomodulatory}

Caffeic acid phenethyl ester is able to inhibit COX (Jung et al., 2008) and lipoxygenase (LOX) (Doiron et al., 2017) enzymes. It is also thought to inhibit the release of arachidonic acid from the cell membrane and, consequently, both the activity of COX-1 and -2 are suppressed. Furthermore, CAPE has been also shown to suppress COX-2 gene expression (Chung et al., 2004; Jung et al., 2008). In contrast, CA is known to inhibit 5- and 12-LOX activity (Yasuko et al., 1984; Doiron et al., 2017), but not COX (Yasuko et al., 1984). Other derivatives have also displayed important inhibiting properties on macrophage NO secretion, which reduces oxidative stress (Zhang J. et al., 2014). Several other CA and CAPE derivatives have been synthesized in recent years to enhance their antiinflammatory action. For example, the substitution of hydroxyl groups in CAPE's catechol ring by methoxy groups is reported to increase its anti-inflammatory action (Zhang P. et al., 2014). Additionally, CAPE is an immunomodulatory molecule which suppresses the transcription of nuclear factor $\kappa \mathrm{B}$ (NF- $\kappa \mathrm{B})$ to lower the expression levels of inflammatory cytokines, such as interleukins 1, 6 and tumor necrosis factor alpha (TNF- $\alpha$ ) (Natarajan et al., 1996). It is believed that CAPE suppresses NF- $\kappa B$ activation by inhibiting its interaction with DNA (Song et al., 2002), and by inhibiting the degradation of inhibitor of nuclear factor kappa B alpha (I $\mathrm{B} \alpha$ ) (Li et al., 2000). In fact, it has been suggested that the anti-inflammatory effect of CAPE is most likely due to ROS inhibition at the transcriptional level through suppression of NF- $\mathrm{KB}$ activation and the direct inhibition of NOS activity (Ito et al., 2005). Finally, CAPE's antiinflammatory and immunomodulatory effects are also thought to be mediated by the reduction of c-jun-N-terminal kinase activity and the regulation of mitogen activated protein kinases (MAPK) signaling pathways (Wang L.C. et al., 2009).

\section{Antioxidant and Radical Scavenging Effects}

The roles of reactive oxygen and nitrogen species (ROS and RNS, respectively) in physiological and pathophysiological processes have become increasingly clear in the past decades. ROS constitute various forms of activated oxygen, including free radicals such as superoxide anion radicals $\left(\mathrm{O}_{2}^{-}\right)$, hydroxyl radicals $\left(\mathrm{OH}^{\circ}\right)$ and non-free radical species such as hydrogen peroxide $\left(\mathrm{H}_{2} \mathrm{O}_{2}\right)$ and singlet oxygen $\left({ }^{1} \mathrm{O}_{2}\right)$. Reactive oxygen species (ROS) are produced by normal physiological processes and play important roles in tissue homeostasis and cell signaling pathways (Carolina et al., 2018). Reactive oxygen species are produced by several mammalian cell enzymes, such as electron transport chain complexes I and III, nicotinamide adenine dinucleotide phosphate (NADPH)-oxidase (NOX), xanthine oxidoreductase (XOR), myeloperoxidase (MPO), NOS and cytochrome P450 enzymes. Nicotinamide adenine dinucleotide phosphate oxidase enzymes catalyze the reduction of molecular oxygen to superoxide anion using NADPH as an electron donor. The sole function of NOX is ROS production for the oxidative burst in phagocytes to kill bacteria. Superoxide has a very short half-life and is rapidly converted to the less-reactive hydrogen peroxide by superoxide dismutase (SOD) enzymes, with hydrogen peroxide being continuously decomposed into water and oxygen by catalase (CAT) enzymes (Burgoyne et al., 2012). Xanthine oxidoreductase is involved in the oxidation of hypoxanthine to xanthine and furthermore to uric acid. It is naturally expressed in the dehydrogenase (XDH) form but, under inflammatory conditions, can be converted into the oxidase (XO) form, which generates superoxide and hydrogen peroxide radicals from molecular oxygen. Myeloperoxidase, found in neutrophils, catalyzes the oxidation of chloride by hydrogen peroxide to form the strong oxidant hypochlorous acid ( $\mathrm{HOCl})$, the prime mediator of oxidative killing in the phagosome of phagocytes. Finally, NOS catalyzes the conversion of L-arginine to nitric oxide (NO) and citrulline using molecular oxygen and reduced nicotinamide-adeninedinucleotide phosphate (NADPH) as co-substrates. The activity of NOS is indirectly modulated by the enzyme arginase, which catalyzes the conversion of L-arginine to ornithine (Durante et al., 2007). Nitric oxide is a local mediator with a vast importance in cardiovascular homeostasis. It acts as a potent vasorelaxant, inhibits platelet aggregation and adhesion, inhibits the interaction of leukocytes with endothelial cells as well as the proliferation and migration of VSM cells (Huang et al., 1995; Loscalzo and Welch, 1995; Furchgott, 1996). Because of these effects, NO exerts an important antiatherosclerotic activity (Kawashima and Yokoyama, 2004). Nitric oxide can also react with superoxide to generate peroxynitrite $\left(\mathrm{OONO}^{-}\right)$, the representative of the reactive nitrogen species (RNS), to also damage cells (Weidinger and Kozlov, 2015). Normally, ROS and RNS are removed by cellular antioxidant systems, such as GSH, glutathione peroxidase (GSH-Px), SOD and CAT. However, when aberrant ROS and RNS production exceeds cells' antioxidant buffering capacity, oxidative and nitrosative stress ensues, respectively, to damage host biological structures like proteins, DNA, and lipids, which can promote inflammation and programmed cell death (Verma et al., 2002; Yellon and Hausenloy, 2007). Cellular or organelle membranes, owing to their high polyunsaturated fatty acids, are particularly susceptible to ROS damage. This type of lipid damage, termed lipid peroxidation, is a process in which free radical species remove electrons from lipids and subsequently produce reactive intermediates that can undergo further reactions. Damaged phospholipids disrupt cellular functions and can also act as cell death signals, inducing programmed cell death (Que et al., 2018). During oxidative and/or nitrosative stress, cellular antioxidant systems (i.e., GSH) are wasted and oxidative products (i.e., malonaldehyde, MDA) increase. In general, the oxidative status of the organism affects many organic functions, including cardiovascular and metabolic. Oxidative and nitrosative stress play important roles in the pathophysiology of cardiovascular diseases, affecting disease progression and clinical outcomes (D’Oria et al., 2020). 


\section{Activity on NOS Isoenzymes}

Nitric oxide synthase comprises the neural (nNOS), inducible (iNOS), and endothelial (eNOS) isoenzymes, which differ in terms of the magnitude and duration by which they release NO. Endothelial and neural NOS are constitutively expressed and release low quantities of NO over long periods of time, exerting several protective effects. Endothelial NOS dilates all types of blood vessels by stimulating soluble guanylyl cyclase and increasing cGMP in VSM cells, where its absence leads to hypertension. When released toward the vascular lumen NO inhibits platelet aggregation and adhesion to the vascular wall, prevents release of platelet-derived growth factors that stimulate smooth muscle proliferation and its production of matrix molecules. Furthermore, it also inhibits leucocyte adhesion and vascular inflammation (Förstermann and Sessa, 2012). Caffeic acid increases the endothelial production of NO in HUVECs by inducing the expression and increasing the activity of eNOS (Wallerath et al., 2005; Gun et al., 2016) or by scavenging ROS, which prevents NO destruction (Migliori et al., 2015). In vivo studies seem to support that CA and CAPE enhance eNOS expression (Khanna et al., 2005; Long et al., 2009; Gun et al., 2016).

Inducible NOS is usually not constitutively expressed, only being upregulated in macrophages after exposure to certain molecular triggers such as endotoxins, cytokines and lipid mediators (Laroux et al., 1995). Macrophages then release large quantities of NO in short periods of time which exert cytotoxic effects on parasitic microorganisms and tumor cells by inhibition in enzymes involved in cellular energetics and DNA stability and replication. Besides being a hallmark of the large majority of auto-immune and inflammatory and diseases, including neurodegeneration, abundant iNOS-generated NO plays a crucial role in septic shock, especially in microvascular damage and lifethreatening hypotension (Förstermann and Sessa, 2012). Caffeic acid phenethyl ester is known to inhibit iNOS expression via suppression of NF- $\mathrm{KB}$ pathway, as well as to directly interfere with its catalytic activity (Song et al., 2002). Both CA and CAPE ameliorate neurodegeneration in $\mathrm{I} / \mathrm{R}$ and chemical injuries in the brain in part by inhibiting iNOS expression. Interestingly, in a study conducted in mice with diabetic nephropathy, where kidney NO content is decreased, CAPE and para-nitro-CAPE enhance the expression of iNOS, preventing further kidney damage (Wang X. et al., 2017). Therefore, it would appear that the activity of CA and its derivatives on iNOS depends on the redox status of the tissue.

Neuronal NOS is involved in several synaptic events including long-term potentiation and long-term inhibition, being implicated in learning, memory and neurogenesis, as well as in the central regulation of blood pressure (Förstermann and Sessa, 2012). However, nNOS overactivity following neuron damaging events (e.g., infarct, inflammation, and excitotoxicity) can greatly increase the concentration of $\mathrm{NO}$ in the brain, leading to oxidative stress and neurotoxicity (Malinski et al., 1993). In brain I/R injury, both iNOS and nNOS are known to be responsible for $\mathrm{NO}$ accumulation and consequent neurotoxicity, whereas eNOS shows a neuroprotective role (Bolaños and Almeida, 1999). Therefore, inhibition of nNOS activity would be expected to improve the pathophysiological outcome. However, the neuroprotection associated with CA and CAPE treatment is predominantly associated with the inhibition of iNOS and COX2, rather than that of nNOS. In fact, in Sprague-Dawley rat pups with brain I/R injury the expression of iNOS is increased, whereas that of nNOS is not. Pretreatment with CAPE at a dose of $40 \mathrm{mg} / \mathrm{kg}$ i.p., for 7 days significantly prevents I/R-induced neonatal brain damage in the cortical, hippocampal and thalamic regions. It inhibits calcium-induced cytochrome $\mathrm{c}$ release as well as iNOS and caspase-1 expression, whereas it does not affect nNOS expression (Wei et al., 2004). Similarly, in a C57BL/6 mouse model of 1-methyl-4-phenyl-1,2,3,6-tetrahydropyridine (MPTP)-induced Parkinson's disease, orally administered CAPE $(2,5$, or $10 \mathrm{mg} / \mathrm{kg} /$ day $)$ for 7 days attenuates dopaminergic degeneration via inhibition of iNOS and caspase-1 expression, whereas it does not affect nNOS expression (Fontanilla et al., 2011). Again, in MPTP-mediated brain inflammation in C57BL/6 mice, $\mathrm{CA}(0.5,1$, and $2 \mathrm{~g}$ per $100 \mathrm{~g}$ diet $)$ administered either before or after I/R injury induction for 4 weeks shows neuroprotective effects by inhibiting the expression of COX-2 and iNOS. The expression of nNOS is decreased when CA is administered before but not after I/R injury (Tsai et al., 2011). In conclusion, further studies should be conducted to confirm the effect of CAPE on nNOS expression in different animal models.

\section{Structure-Activity Relationship}

The antioxidant activity of CA and its derivatives, at least in cellular systems in vitro, the closest to in vivo conditions, is dependent not only on the molecular structure, but also on the solubility, hydrophobicity and stability of the compounds (Wu W.M. et al., 2007). Caffeic acid and CAPE are able to scavenge both reactive oxygen and nitrogen species, in acellular and in cellular systems (Yan-Chun and Rong-Liang, 1991; Kono et al., 1997; Wu W.M. et al., 2007; Kassim et al., 2014). In the former CA and CAPE inhibit lipid peroxidation to a higher extent than $\alpha$-tocopherol (Wu W.M. et al., 2007; Göçer and Gülçin, 2011). Caffeic acid prevents the chain initiation of lipid peroxidation by scavenging peroxyl radical (LOO') (Wu W.M. et al., 2007). Caffeic acid has also been shown to maintain proteins against oxidation by scavenging ROS and by assisting in their repair through transfer of electrons to amino acid radicals (Zhu et al., 2006). Additionally, part of the antioxidant effectiveness of CA and CAPE may lie in their ability to chelate transition metals such as iron and copper (Nardini et al., 1995). Finally, by inhibiting transcription factors (i.e., NF- $\mathrm{KB}$ ) and enzymes (i.e., COX and LOX) indirectly involved in oxidative stress, CA and CAPE also exert important antioxidant activity. Antioxidant and free radical scavenging activities are attributed to several functional groups in the CA molecular structure, with the orthodihydroxyl functionality in the catechol ring being probably the best studied so far (Son and Lewis, 2002; Wu W.M. et al., 2007; Wang X. et al., 2010; Doiron et al., 2017). When CA is oxidized by ROS its intermediate radicals can be stabilized by these adjacent electron-donating hydroxy functions, and the free radical chain reaction may be terminated (Graf, 1992). By containing an unsaturated bond the CA ethylenic side chain ensures greater hydrogen donating ability and is therefore able to stabilize the 
phenoxy radical by resonance or to provide an additional site for reaction with ROS (Graf, 1992; Barone et al., 2009; Mathew et al., 2015). In fact, this side chain is responsible for the relatively greater activity of hydroxycinnamic acids compared to their hydroxybenzoic acid counterparts (Göçer and Gülçin, 2011). The esterification of caffeic acid forms compounds with increased lipophilicity, which might facilitate their interaction with membrane phospholipids and enhance their antioxidant properties, especially against lipid peroxidation (Son and Lewis, 2002; Wu W.M. et al., 2007). With regards to CAPE and its derivatives, the ester function is thought to play an important role in NO inhibition (Nagaoka et al., 2003). Finally, the presence of hydrogen-donating substituents such as the $-\mathrm{NH}$ group can also be responsible for enhancing the antioxidant activity of CA amidated derivatives (Son and Lewis, 2002; Barbakadze et al., 2005).

\section{Cytoprotection on Endothelial Cells}

Essentially due to their radical scavenging and antioxidant properties, CA and its derivatives have also shown cytoprotective effects on cardiovascular cells in vitro, such as vascular endothelial cells and cardiomyocytes. Caffeic acid, CAPE and CAPA show cytoprotective effects in human umbilical vein endothelial cells (HUVECs). Caffeic acid enhances basal and acetylcholine-induced endothelial NO production in a dosedependent manner under hypoxia and while incubated with uremic toxins. This is not attributed to the induction of eNOS by CA but rather to its ROS scavenging activity, by which it prevents oxidative stress (Migliori et al., 2015). In fact, CA prevents oxidation of low-density lipoprotein (LDL) and the consequent rise in calcium concentration, therefore preventing apoptosis (Vieira et al., 1998). Dihydrocaffeic acid (DHCA) prevents oxidative stress in EA.hy926 endothelial cells, a permanent cell line derived from HUVECs that expresses factor VIII antigen, oxidizes LDL, and displays calcium-dependent stimulation of eNOS. In this cell line DHCA scavenges ROS and increases eNOS expression (Huang et al., 2004). Caffeic acid phenethyl ester produces concentration-dependent protection against menadione-induced cytotoxicity in HUVECs, and also prevents apoptosis. However, at high doses CAPE's cytoprotective effect decreases, probably due to cytotoxicity. Curiously, this cytoprotective effect is shared by two CAPE fluorinated analogs but not by CA itself (Wang X. et al., 2006), which should prompt further research into the structure-activity relations. Again in menadione-induced toxicity endothelial cells, CAPE's cytoprotective effect is mediated by the upregulation of heme oxidase-1 (HO-1) via transcriptional activation (Wang X. et al., 2008). Heme oxygenase- 1 catalyzes the conversion of heme group into biliverdin, carbon monoxide and iron. Biliverdin is then converted to bilirubin by bilirubin reductase. Reactive oxygen species react with bilirubin, converting it back to biliverdin. By increasing the pool of biliverdin, HO-1 acts as an antioxidant enzyme, shifting the redox state to a reduce state and decreases superoxide formation (Turkseven et al., 2005). Interestingly, in fluorinated CAPE derivatives, cytoprotective effect is correlated with the upregulation of HO-1 but not with direct antioxidant effect (Wang X. et al., 2010). Caffeic acid phenethyl amide and two fluorinated compounds (FCAPA-1, FCAPA-2) have also shown cytoprotective effects in HUVECs. In particular, these compounds were shown to protect HUVECs against hydrogen peroxide-induced oxidative damage (Wang T. et al., 2008; Yang J. et al., 2010). Other CAPE and CAPA fluorinated compounds were shown to be toxic, although the origin for these differences is presently not clear.

\section{Cytoprotection on Cardiomyocytes}

Caffeic acid, CAPE and CAEA display cardioprotective properties in several animal models of myocardial injury mediated by hydrogen peroxide (Izuta et al., 2009), cadmium (Mollaoglu et al., 2006), doxorubicin (Fadillioglu et al., 2004), rotenone (Akpinar et al., 2005), isoproterenol (Oktar et al., 2010; Paeng et al., 2015) and electromagnetic radiation (Ozguner et al., 2005; Mansour and Tawfik, 2012). Pyrrolidinyl caffeamide (PLCA) shows higher ROS scavenging and cytoprotective effects than $\mathrm{CA}$ in cardiomyocytes exposed to hydrogen peroxide (Ku et al., 2016). Caffeic acid protects against isoproterenol-induced myocardial infarction in Wistar rats. Isoproterenol toxicity leads to the decrease of several antioxidant enzymes in cardiomyocytes including SOD, CAT, and GSH-Px and to the increase of lipid peroxides. Pretreatment with CA (15 mg/kg for 10 days) increased SOD, CAT, and GSH-Px activities, decreased cardiac peroxidation markers and improved myocardial tissue histology (Kumaran and Prince, 2010). Caffeic acid ethanolamine (CAEA) has shown superior myocardial-protective activity compared to CA itself. In isoproterenol-induced cardiomyocyte toxicity, CAEA improves cellular and mitochondrial oxidative stress by increasing manganese SOD activity. Furthermore, it reverses cellular energetics and preserves cardiac mechanical performance in a sirtuin-dependent mechanism and prevents cardiac remodeling, namely ventricular hypertrophy fibrosis (Lee et al., 2015b). Caffeic acid phenethyl ester also displays cardiac remodeling properties. In a model of pressure overloadinduced myocardial hypertrophy, CAPE attenuates cardiac remodeling through down-regulation of the MEK/ERK signaling pathway in vivo and in vitro (Ren et al., 2017). Long-term CAPE supplementation (15 mg/kg/day for 95 days i.p.) in SpragueDawley rats increases the levels of antioxidant mediators and lowers MDA levels in the cardiomyocytes and aorta of senescent animals, which suggests that long-term supplementation may prevent both myocardial damage and vascular remodeling (Eşrefoglu et al., 2011). The fibrosis preventing activity of CAPE may be associated with the inhibition of myofibroblast formation and collagen synthesis (Mia and Bank, 2016). In an animal model of cadmium-induced atrial and ventricular hypertrophy, CAPE's cardioprotection seems to be attributed at least to its antioxidant activity, namely the inhibition of lipid peroxidation and reduction of MDA and NO (Mollaoglu et al., 2006). Caffeic acid phenethyl ester (CAPE) also protects rat cardiomyocytes from hydrogen peroxide-induced oxidative injury by lowering MDA levels and increasing SOD and GSH-Px activities (Izuta et al., 2009). Early treatment with CAPE (10 mM/kg i.p. for 7 days) also protects Sprague-Dawley rat hearts from gamma radiation-induced injury owing to its antioxidant activity, as shown by the down-regulation of 
MDA, XO and adenosine deaminase (ADA), together with the up-regulation of nitrate/nitrite and SOD activity (Mansour and Tawfik, 2012). In rats subjected to electromagnetic radiation (900 MHz, $30 \mathrm{~min} /$ day, for 10 days) to evoke ROS production, CAPE (10 mM/mL/kg/day i.p., for 10 days) reduces MDA levels in the myocardium, while increasing the activity of SOD, CAT and GSH-Px (Ozguner et al., 2005). In a rat model of endotoxin-induced cardiac stress, CAPE restores several parameters indicating cardiomyocyte injury, including creatine kinase (CK) and lactate dehydrogenase (LDH), MDA, TNF- $\alpha$, GSH, serum and cardiac nitrite/nitrate, as well as GPx and MPO activities, besides inducing HO-1 levels (Motawi et al., 2011). Finally, by suppressing NF- $\kappa$ B pathway, CAPE decreases the expression of iNOS and COX-2 enzymes and the release of pro-inflammatory cytokines such as TNF- $\alpha$, leading to the decrease of ROS production (Natarajan et al., 1996).

\section{Role in Ischemia/Reperfusion Injury}

Ischemia is an important trigger for tissue architectural and functional dysfunction as it restricts the delivery of oxygen and nutrients to organs and tissues. The extent of organ damage depends on the duration and degree of perfusion restriction, and on the organ's biomolecular composition, levels of antioxidant defenses and metabolic rate (Wu M.Y. et al., 2018). Ischemia is a hallmark of several cardiovascular diseases, such as ischemic heart disease, peripheral artery disease and stroke (Johnson et al., 2019). During the ischemic period, cellular ATP stores are depleted by conversion into hypoxanthine and AMP. Xanthine dehydrogenase is converted into xanthine oxidase (XO), which converts hypoxanthine into uric acid (Johnson et al., 2019). From these processes, ROS are produced. Ischemia is also known to lead to endothelial dysfunction by increasing vascular permeability, and often leads to leukocyte infiltration and edema (Yang Q. et al., 2016). Albeit essential for preventing further tissue damage, the subsequent reperfusion process also happens to be deleterious to tissue due to oxygen overload, which leads to a massive ROS production by XO. Additionally, infiltrated leukocytes can lead to tissue damage by also secreting ROS themselves, as well as enzymes. Reactive oxygen species damage tissues by promoting lipid peroxidation and protein carbamylation (Verbrugge et al., 2015), which compromise the structure and function of cellular membranes, and lead to cell dysfunction and death via necrosis and/or apoptosis.

Caffeic acid, PLCA, CAPE, and nitro-CAPE derivatives have shown a very high potential for preventing and attenuating tissue damage caused by ischemia/reperfusion (I/R) injury in many organs in vivo and in vitro, including the myocardium (Ozer et al., 2004; Cagli et al., 2005; Huang et al., 2005; Parlakpinar et al., 2005; Tan et al., 2005; Özeren et al., 2005; Ince et al., 2006; Ho et al., 2013; Castellano et al., 2016), skeletal muscle (Cagli et al., 2005; Ozyurt et al., 2006, 2007; Andrade-Silva et al., 2009), brain (Irmak et al., 2001; Tsai et al., 2006; Altuğ et al., 2008), spinal cord (Ilhan et al, 1999), liver (Feng et al., 2008; SaavedraLopes et al., 2008), kidney (Irmak et al., 2001; Gurel et al., 2004; Ozer et al., 2005a; Migliori et al., 2015), intestine (Koltuksuz et al., 1999; Sato et al., 2011; Teke et al., 2012, 2013), retina (Shi et al., 2010), ovary (Celli et al., 2004; Kart et al., 2009), testes (Koltuksuz et al., 2000; Eşrefoglu et al., 2005; Atik et al., 2006), and skin flaps (Aydogan et al., 2007; Yeǧin et al., 2020). Nearly all the studies conducted on the beneficial properties of these compounds on I/R injury agree that they are due to their potent ROS scavenging, antioxidant and anti-inflammatory activities. Regarding the cardiac I/R injury, these compounds normalize several biochemical changes associated with I/R injury. In particular, they increase CAT, GSH-Px and SOD activities, while reducing MDA levels, reflecting their antioxidant activity (Du et al., 2016; Li et al., 2018). They also decrease neutrophil infiltration, as observed by the decrease in MPO activity, further preventing oxidative injury and improves cardiac mechanical performance (Ku et al., 2016). In addition, these compounds suppress pro-apoptotic factors expression while upregulating anti-apoptotic factors (Du et al., 2016; Li et al., 2018). Pyrrolidinyl caffeamide in particular was shown to activate the PI3K-Akt pathway, leading to the activation of HO-1 enzyme, while stabilizing SOD and CAT activities (Ku et al., 2016). Pyrrolidinyl caffeamide also induces phosphorylation of protein kinase $B$ (AKT) and AMP-activated protein kinase (AMPK), which leads to an increased expression of GLUT4 transporters, improving cellular energetics, and to the reduction of pro-apoptotic factors, improving cell survival (Lee et al., 2015a). Collectively, these effects contribute to a significant reduction in myocardial infarct size (Ozer et al., 2004; Cagli et al., 2005; Huang et al., 2005; Parlakpinar et al., 2005; Özeren et al., 2005; Ince et al., 2006; Ho et al., 2013; Castellano et al., 2016; Du et al., 2016; Li et al., 2018 ) and to an improvement in mechanical performance (Ku et al., 2016). Finally, the protective effect of CA and its derivatives over vascular endothelial cells facilitates reperfusion, leading to an increase in nutrient supply and waste product removal, as well as to the decrease in the migration of damaging mononuclear cells (Wang X. et al., 2006; Li et al., 2018).

\section{Anti-atherosclerotic Activity}

Atherosclerosis is an inflammatory process consisting in the formation of a fatty plaque in the intimal layer of arteries, whose growth with time leads to progressive vascular lumen narrowing and to consequent perfusion reduction. The process begins with the uptake of LDLs carried in the bloodstream, a process that is stimulated by high levels of sheer stress on the endothelium. Upon accessing the intimal layer, LDLs are oxidized and taken up by macrophages which become foam cells and secrete cytokines to attract other leukocytes and growth factors. Consequently, VSM cells undergo considerable hypertrophy and hyperplasia. Over time, the fatty plaque is calcified, becomes hard, and is more susceptible to break and to acute vessel occlusion (Bergheanu et al., 2017).

Caffeic acid is described as an inhibitor of LDL oxidation, preventing atherosclerosis (Wang and Yang, 2012). Caffeic acid phenethyl ester has benefits for preventing the progression of atherosclerosis in vitro and in several animal models in vivo. In apolipoprotein E-deficient mice, oral CAPE administration (30 $\mathrm{mg} / \mathrm{kg}$ for 12 weeks) ameliorates the atherosclerosis progress. It has been shown that CAPE inhibits NF- $\kappa$ B and related genes, such as TNF- $\alpha$, interleukin 2, platelet-derived growth factor (PDGF) and E-selectin, in the aorta (Hishikawa et al., 2005) to, 
therefore, prevent the infiltration of leukocytes in the plaque milieu. Besides initiating atherosclerosis, LDL uptake is also associated with other hazardous changes in the cardiovascular system; for example, apoptosis of endothelial cells and increased expression of angiotensin II receptor, where the latter contributes to increase blood pressure (Sumners et al., 2015). In in vitro terms, pretreatment of human coronary artery endothelial cells with CAPE prevents the oxidized LDL (oxLDL) and TNF- $\alpha$ mediated increase in angiotensin II receptor expression, which is thought to be achieved through NF- $\kappa \mathrm{B}$ suppression ( $\mathrm{Li}$ et al., 2000). In another study, CAPE has been found to inhibit oxLDL-induced apoptosis in human aortic endothelial cells, achieved by the action of the lectin-like endothelial receptor for oxLDL (Li and Mehta, 2000). Caffeic acid phenethyl ester also has beneficial effects on the smooth muscle layer. It inhibits angiotensin II, PDGF-induced proliferation and the migration of VSM cells, this last case via the activation of p38 MAPK, hypoxia inducible factor- $1_{\alpha}$ (HIF-1 $1_{\alpha}$ ), and HO-1 (Roos et al., 2011). Caffeic acid phenethyl ester inhibits the re-stenosis of injured carotid arteries of rats, probably due to the combination of NF$\kappa \mathrm{B}$ pathway inhibition, ROS scavenging, COX-2 inhibition and neointima apoptosis (Maffia et al., 2002). Diabetes is a marked factor that accelerates atherosclerosis. Caffeic acid phenethyl ester suppresses diabetes-induced atherosclerotic manifestations without affecting the developed hyperglycemia, particularly by preventing collagen deposition and, consequently, arterial stiffening (Hassan et al., 2014).

\section{Anti-angiogenic Activity}

Angiogenesis refers to the tightly controlled and complex process of the formation of new blood vessels from pre-existing essential vessels for tissue development, regeneration and repair (Tahergorabi and Khazaei, 2012). Angiogenesis contributes to the growth of tumors, especially for the development of metastases. It is also a histological hallmark of atherosclerotic lesions, where it contributes to fatty plaque destabilization (Camaré et al., 2017) and occurs in peripheral arterial disease, where it contributes to tissue reperfusion (Inampudi et al., 2018). The angiogenesis process lies in a balance between promoting and suppressing factors. Angiogenesis is initiated when tissues sense a hypoxic environment by responding with the stabilization and translocation of transcription factor hypoxia-inducible factor 1alpha $\left(\mathrm{HIF}_{\alpha}\right)$ to the nucleus, where it induces angiogenic factors like vascular endothelium growth factor (VEGF) (Potente and Carmeliet, 2017). This factor is then released and binds to the VEGF2 receptor in neighboring endothelial cells to increase NOX activity, which leads to ROS production. This oxidizing environment activates many intracellular signaling pathways that lead to proliferation, migration and tube formation by endothelial cells (Fukai masuko and Nakamura, 2008). Vascular endothelium growth factor (VEGF) and other proangiogenic factors lead ROS themselves to increase VEGF secretion in tissues by reinforcing the neovascularization process (Kim and Byzova, 2014). Changes in the extracellular matrix, brought about by degrading enzymes (i.e., matrix metalloproteinase 9, MMP9) secreted by infiltrating neutrophils and by ROS, are also potent inducers of angiogenesis (Quintero-Fabián et al., 2019).
Caffeic acid phenethyl ester has inhibitory effects on various cancer cell lines, including lung cancer, melanoma, glioma and pancreatic cancer, colon cancer, breast cancer and neuroblastoma (Wu J. et al., 2011; Firat et al., 2019) both in vitro and in vivo. Caffeic acid, CAPE and synthetic derivative CADPE [3-(3,4Dihydroxy-phenyl)-acrylic acid 2-(3,4-dihydroxy-phenyl)-ethyl ester], later found to be a naturally occurring compound also called teucrol, have shown anti-angiogenic effects on both cancer cell lines and the cell lines of diverse organs (Jung et al., 2007). The anti-angiogenic effects of CAPE have been demonstrated in vitro in chorioallantoic membrane (Song et al., 2002) and bovine capillary cell models (Wu J. et al., 2011), and in several models of cancer-bearing animals in vivo. These studies have established that CAPE's antioxidant and anti-inflammatory properties are important for suppressing the angiogenesis process. (Ahn et al., 2009). Firstly, CAPE suppresses VEGF secretion both in vitro (cancer cell lines) and in vivo (tumor-bearing animals) (Liao et al., 2003; Paeng et al., 2015), an effect shared by CAPDE (Jung et al., 2007). This has been partly attributed to ROS scavenging and to the inhibition of the PI3K-Akt and HIF- $1_{\alpha}$ signaling pathways (Jung et al., 2007; Paeng et al., 2015). In vitro, CAPE also inhibits tube formation in HUVECs in a concentration-dependent manner (Liao et al., 2003; Ahn et al., 2009), besides showing antiproliferative activity of endothelial cells (Grunberger et al., 1988). Secondly, through its anti-inflammatory (LOX inhibition) and immunomodulatory (NF- $\mathrm{B}$ suppression) properties, CAPE inhibits corneal neovascularization (Totan et al., 2001). Strikingly, CAPE has also been found to induce the activation of the NF- $\kappa$ B pathway and to promote VEGF expression in a dental pulp cell line (Kuramoto et al., 2019). This leads to the conclusion that the effect of CAPE on NF- $\kappa$ B and the angiogenic process is not as straightforward as previously believed, and differences in cell lines may explain this new found variability. Thirdly, CAPE is also able to interfere with the extracellular matrix modifications brought about by the leukocyte infiltration present in carcinogenesis by reducing the expression and inhibiting the activity of pro-angiogenic matrix metalloproteinases (Chung et al., 2004; El-Refaei and El-Naa, 2010; Wu S. et al., 2017), and by independently increasing the expression of angiostatic factors (El-Refaei and El-Naa, 2010) and shifting the equilibrium toward angiogenesis suppression.

\section{CONCLUSION}

Caffeic acid and its derivatives display major actions on the cardiovascular system. Several compounds (CA, CAPE, and CAPA) display relevant vasorelaxant activity and attributed to diverse cellular mechanisms. Besides their vasorelaxant activity, CA and CAPE also lower heart rate and suppress the renin-angiotensin-aldosterone axis, which explains their blood pressure-lowering activity. However, there is a notable shortage of in vivo studies that center on exploring effects on perfusion. Furthermore, the pharmacokinetic profile of some CA derivatives is still lacking in both animals and human subjects, which should prompt further studies. Caffeic acid phenethyl 
ester is the most studied compound, and shows marked antiatherosclerotic and anti-angiogenic effects, as well as protection against ischemia/reperfusion lesions, which is why it is the one with the highest potential highest potential for translation into clinical medicine.

\section{REFERENCES}

Agunloye, O. M., Oboh, G., Ademiluyi, A. O., Ademosun, A. O., Akindahunsi, A. A., Oyagbemi, A. A., et al. (2019). Cardio-protective and antioxidant properties of caffeic acid and chlorogenic acid: mechanistic role of angiotensin converting enzyme, cholinesterase and arginase activities in cyclosporine induced hypertensive rats. Biomed. Pharmacother. 109, 450-458. doi: 10.1016/j. biopha.2018.10.044

Ahn, M. R., Kunimasa, K., Kumazawa, S., Nakayama, T., Kaji, K., Uto, Y., et al. (2009). Correlation between antiangiogenic activity and antioxidant activity of various components from propolis. Mol. Nutr. Food Res. 53, 643-651. doi: 10.1002/mnfr.200800021

Akpinar, M. B., Erdogan, H., Sahin, S., Ucar, F., and Ilhan, A. (2005). Protective effects of caffeic acid phenethyl ester on rotenone-induced myocardial oxidative injury. Pestic. Biochem. Physiol. 82, 233-239. doi: 10.1016/j.pestbp.2005.03.003

Altuğ, M. E., Serarslan, Y., Bal, R., Kontaş, T., Ekici, F., Melek, I. M., et al. (2008). Caffeic acid phenethyl ester protects rabbit brains against permanent focal ischemia by antioxidant action: a biochemical and planimetric study. Brain Res. 1201, 135-142. doi: 10.1016/j.brainres.2008.01.053

Andrade-Silva, A. R., Ramalho, F. S., Ramalho, L. N. Z., Saavedra-Lopes, M., Jordão, A. A., Vanucchi, H., et al. (2009). Effect of NFкB inhibition by CAPE on skeletal muscle ischemia-reperfusion injury. J. Surg. Res. 153, 254-262. doi: 10.1016/j.jss.2008.04.009

Andriambeloson, E., Magnier, C., Haan-Archipoff, G., Lobstein, A., Anton, R., Beretz, A., et al. (1998). Natural dietary polyphenolic compounds cause endothelium-dependent vasorelaxation in rat thoracic aorta. J. Nutr. 128, 23242333. doi: $10.1093 / \mathrm{jn} / 128.12 .2324$

Arasoglu, T., Derman, S., and Mansuroglu, B. (2016). Comparative evaluation of antibacterial activity of caffeic acid phenethyl ester and PLGA nanoparticle formulation by different methods. Nanotechnology 27:025103. doi: 10.1088/ 0957-4484/27/2/025103

Atik, E., Görür, S., and Kiper, A. N. (2006). The effect of caffeic acid phenethyl ester (CAPE) on histopathological changes in testicular ischemia-reperfusion injury. Pharmacol. Res. 54, 293-297. doi: 10.1016/j.phrs.2006.06.005

Aydogan, H., Gurlek, A., Parlakpinar, H., Askar, I., Bay-Karabulut, A., Aydogan, N., et al. (2007). Beneficial effects of caffeic acid phenethyl ester (CAPE) on the ischaemia-reperfusion injury in rat skin flaps. J. Plast. Reconstr. Aesthetic. Surg. 60, 563-568. doi: 10.1016/j.bjps.2006.01.030

Bankova, V., Trusheva, B., and Popova, M. (2018). Caffeic acid phenethyl ester (CAPE) - Natural sources, analytical procedures and synthetic approaches. Comptes Rendus L'Academie Bulg Des Sci 71, 1157-1169.

Barbakadze, V. V., Kemertelidze, E. P., Targamadze, I., Mulkidzhanyan, K., Kemink, J., Van Den Berg, A. J. J., et al. (2005). Poly[3-(3,4dihydroxyphenyl)glyceric acid] from stems of Symphytum asperum and S. caucasicum. Chem. Nat. Compd. 41, 374-377. doi: 10.1007/s10600-0050155-2

Barone, E., Calabrese, V., and Mancuso, C. (2009). Ferulic acid and its therapeutic potential as a hormetin for age-related diseases. Biogerontology 10, 97-108. doi: 10.1007/s10522-008-9160-8

Barros Silva, R., Santos, N. A. G., Martins, N. M., Ferreira, D. A. S., Barbosa, F., Oliveira Souza, V. C., et al. (2013). Caffeic acid phenethyl ester protects against the dopaminergic neuronal loss induced by 6-hydroxydopamine in rats. Neuroscience 233, 86-94. doi: 10.1016/j.neuroscience.2012.12.041

Beltrán-Ramírez, O., Alemán-Lazarini, L., Salcido-Neyoy, M., Hernández-García, S., Fattel-Fazenda, S., Arce-Popoca, E., et al. (2008). Evidence that the anticarcinogenic effect of caffeic acid phenethyl ester in the resistant hepatocyte model involves modifications of cytochrome P450. Toxicol. Sci. 104, 100-106. doi: $10.1093 /$ toxsci/kfn071

Bergheanu, S. C., Bodde, M. C., and Jukema, J. W. (2017). Pathophysiology and treatment of atherosclerosis: current view and future perspective on lipoprotein

\section{AUTHOR CONTRIBUTIONS}

HS and NL contributed literature research. HS contributed manuscript editing. Both authors contributed to the article and approved the submitted version.

modification treatment. Netherlands Hear J. 25, 231-242. doi: 10.1007/s12471017-0959-2

Bhullar, K. S., Lassalle-Claux, G., Touaibia, M., and Vasantha Rupasinghe, H. P. (2014). Antihypertensive effect of caffeic acid and its analogs through dual renin-angiotensin-aldosterone system inhibition. Eur. J. Pharmacol. 730, 125132. doi: 10.1016/j.ejphar.2014.02.038

Bolaños, J. P., and Almeida, A. (1999). Roles of nitric oxide in brain hypoxiaischemia. Biochim. Biophys. Acta Bioenerg. 1411, 415-436. doi: 10.1016/s00052728(99)00030-4

Burgoyne, J. R., Mongue-Din, H., Eaton, P., and Shah, A. M. (2012). Redox signaling in cardiac physiology and pathology. Circ. Res. 111, 1091-1106. doi: 10.1161/circresaha.111.255216

Cagli, K., Bagci, C., Gulec, M., Cengiz, B., Akyol, O., Sari, I., et al. (2005). In vivo effects of caffeic acid phenethyl ester on myocardial ischemia-reperfusion injury and apoptotic changes in rats. Ann. Clin. Lab Sci. 35, 440-448.

Camaré, C., Pucelle, M., Nègre-Salvayre, A., and Salvayre, R. (2017). Angiogenesis in the atherosclerotic plaque. Redox Biol. 12, 18-34. doi: 10.1016/j.redox.2017. 01.007

Carolina, A. F., Ni, D., Rosenkrans, Z. T., and Cai, W. (2018). Scavenging of reactive oxygen and nitrogen species with nanomaterials. Nano Res. 11, 4955-4984. doi: 10.1007/s12274-018-2092-y

Castellano, A. J., Kuhn, T., Liu, S., Kucharski, K., Venditto, J., Kuo, D., et al. (2016). The cardioprotective effects of caffeic acid phenethyl ester (CAPE). on myocardial ischemia / reperfusion (I / R). injury. FASEB J. 30:1207.2.

Çeçen, S., Ek, R. O., and Y1ld1z, Y. (2016). Vascular effects of caffeic acid phenethyl ester (CAPE) on isolated thoracic aorta of ovariectomized rats. Biomed. Res. 2016, S469-S472.

Celli, N., Dragani, L. K., Murzilli, S., Pagliani, T., and Poggi, A. (2007). In vitro and in vivo stability of caffeic acid phenethyl ester, a bioactive compound of propolis. J. Agric. Food Chem. 55, 3398-3407. doi: 10.1021/jf063477o

Celli, N., Mariani, B., Dragani, L. K., Murzilli, S., Rossi, C., and Rotilio, D. (2004). Development and validation of a liquid chromatographic-tandem mass spectrometric method for the determination of caffeic acid phenethyl ester in rat plasma and urine. J. Chromatogr. B 810, 129-136. doi: 10.1016/s1570-0232(04) 00599-9

Chang, G. J., Chang, C. J., Chen, W. J., Yeh, Y. H., and Lee, H. Y. (2013). Electrophysiological and mechanical effects of caffeic acid phenethyl ester, a novel cardioprotective agent with antiarrhythmic activity, in guinea-pig heart. Eur. J. Pharmacol. 702, 194-207. doi: 10.1016/j.ejphar.2013.01.040

Chung, T., Moon, S., Chang, Y., Ko, J., Lee, Y., Cho, G., et al. (2004). Novel and therapeutic effect of caffeic acid and caffeic acid phenyl ester on hepatocarcinoma cells: complete regression of hepatoma growth and metastasis by dual mechanism. FASEB J. 18, 1670-1681. doi: 10.1096/fj.04-2126com

Cicala, C., Morello, S., Iorio, C., Capasso, R., Borrelli, F., and Mascolo, N. (2003). Vascular effects of caffeic acid phenethyl ester (CAPE) on isolated rat thoracic aorta. Life Sci. 73, 73-80. doi: 10.1016/s0024-3205(03)00235-2

Cotecchia, S. (2010). The $\alpha 1$-adrenergic receptors: diversity of signaling networks and regulation. J. Recept. Signal Transduct. 30, 410-419. doi: 10.3109/10799893. 2010.518152

Del Rio, D., Rodriguez-Mateos, A., Spencer, J. P. E., Tognolini, M., Borges, G., and Crozier, A. (2013). Dietary (poly)phenolics in human health: structures, bioavailability, and evidence of protective effects against chronic diseases. Antioxidants Redox Signal. 18, 1818-1892. doi: 10.1089/ars.2012.4581

Doiron, J. A., Leblanc, L. M., Hébert, M. J. G., Levesque, N. A., Paré, A. F., Jean-François, J., et al. (2017). Structure-activity relationship of caffeic acid phenethyl ester analogs as new 5-lipoxygenase inhibitors. Chem. Biol. Drug Des. 89, 514-528. doi: 10.1111/cbdd.12874

D’Oria, R., Schipani, R., Leonardini, A., Natalicchio, A., Perrini, S., Cignarelli, A., et al. (2020). The role of Oxidative stress in cardiac disease: from physiological response to injury factor. Oxid. Med. Cell Longev. 2020:5732956. 
Du, Q., Hao, C., Gou, J., Li, X., Zou, K., He, X., et al. (2016). Protective effects of p-nitro caffeic acid phenethyl ester on acute myocardial ischemia-reperfusion injury in rats. Exp. Ther. Med. 11, 1433-1440. doi: 10.3892/etm.2016.3070

Duman, I., Soner, B. C., Inan, S. Y., and Sahin, A. S. (2014). Effects of caffeic acid phenethyl ester on isolated human umbilical arteries precontracted with endothelin and prostaglandin F2ALPHA. Clin. Ther. 36:e5. doi: 10.1016/j. clinthera.2014.05.020

Durante, W., Johnson, F. K., and Johnson, R. A. (2007). Arginase: a critical regulator of nitric oxide synthesis and vascular function. Clin. Exp. Pharmacol. Physiol. 34, 906-911. doi: 10.1111/j.1440-1681.2007.04638.x

El-Bassossy, H. M., El-Fawal, R., and Fahmy, A. (2012). Arginase inhibition alleviates hypertension associated with diabetes: effect on endothelial dependent relaxation and NO production. Vascul. Pharmacol. 57, 194-200. doi: 10.1016/j. vph.2012.01.001

El-Refaei, M. F., and El-Naa, M. M. (2010). Inhibitory effect of caffeic acid phenethyl ester on mice bearing tumor involving angiostatic and apoptotic activities. Chem. Biol. Interact. 186, 152-156. doi: 10.1016/j.cbi.2010.04.019

El-Seedi, H. R., El-Said, A. M. A., Khalifa, S. A. M., Göransson, U., Bohlin, L., Borg-Karlson, A. K., et al. (2012). Biosynthesis, natural sources, dietary intake, pharmacokinetic properties, and biological activities of hydroxycinnamic acids. J. Agric. Food Chem. 60, 10877-10895. doi: 10.1021/jf301807g

Erdemli, H., Akyol, S., Armutcu, F., and Akyol, O. (2015). Antiviral properties of caffeic acid phenethyl ester and its potential application. J. Intercult. Ethnopharmacol. 4, 344-347. doi: 10.5455/jice.20151012013034

Eşrefoglu, M., Gül, M., Ateş, B., and Erdoğan, A. (2011). The effects of caffeic acid phenethyl ester and melatonin on age-related vascular remodeling and cardiac damage. Fundam. Clin. Pharmacol. 25, 580-590. doi: 10.1111/j.14728206.2010.00876.x

Eşrefoglu, M., Gül, M., Parlakpinar, H., and Acet, A. (2005). Effects of melatonin and caffeic acid phenethyl ester on testicular injury induced by myocardial ischemia/reperfusion in rats. Fundam. Clin. Pharmacol. 19, 365-372. doi: 10. 1111/j.1472-8206.2005.00331.x

Fadillioglu, E., Oztas, E., Erdogan, H., Yagmurca, M., Sogut, S., Ucar, M., et al. (2004). Protective effects of caffeic acid phenethyl ester on doxorubicin-induced cardiotoxicity in rats. J. Appl. Toxicol. 24, 47-52. doi: 10.1002/jat.945

Feng, Y., Lu, Y. W., Xu, P. H., Long, Y., Wu, W. M., Li, W., et al. (2008). Caffeic acid phenethyl ester and its related compounds limit the functional alterations of the isolated mouse brain and liver mitochondria submitted to in vitro anoxia-reoxygenation: relationship to their antioxidant activities. Biochim. Biophys. Acta Gen. Subj. 1780, 659-672. doi: 10.1016/j.bbagen.2008. 01.002

Firat, F., Özgül, M., Türköz Uluer, E., and Inan, S. (2019). Effects of caffeic acid phenethyl ester (CAPE) on angiogenesis, apoptosis and oxldatlve stress in various cancer cell lines. Biotech. Histochem. 94, 491-497. doi: 10.1080/ 10520295.2019.1589574

Fontanilla, C. V., Ma, Z., Wei, X., Klotsche, J., Zhao, L., Wisniowski, P., et al. (2011). Caffeic acid phenethyl ester prevents 1-methyl-4-phenyl-1,2,3,6tetrahydropyridine-induced neurodegeneration. Neuroscience 188, 135-141. doi: 10.1016/j.neuroscience.2011.04.009

Förstermann, U., and Sessa, W. C. (2012). Nitric oxide synthases: regulation and function. Eur. Heart J. 33, 829-837. doi: 10.1093/eurheartj/ehr304

Fukai masuko, U., and Nakamura, Y. (2008). Reactive Oxygen species and angiogenesis NADPH Oxidase as. Cancer Lett. 266, 37-52. doi: 10.1016/j.canlet. 2008.02.044

Furchgott, R. F. (1996). The discovery of endothelium-derived relaxing factor and its importance in the identification of nitric oxide. J. Am. Med. Assoc. 276, 1186-1188. doi: 10.1001/jama.1996.03540140074032

Gaglione, M., Malgieri, G., Pacifico, S., Severino, V., D’Abrosca, B., Russo, L., et al. (2013). Synthesis and biological properties of caffeic acid-PNA dimers containing guanine. Molecules 18, 9147-9162. doi: 10.3390/molecules 18089147

Göçer, H., and Gülçin, I. (2011). Caffeic acid phenethyl ester (CAPE): correlation of structure and antioxidant properties. Int. J. Food Sci. Nutr. 62, 821-825. doi: 10.3109/09637486.2011.585963

Godfraind, T., Miller, R., and Wibo, M. (1986). Calcium antagonism and calcium entry blockade. Pharmacol. Rev. 38, 321-416.

Graf, E. (1992). Antioxidant potential of ferulic acid. Free Radic. Biol. Med. 13, 435-448. doi: 10.1016/0891-5849(92)90184-i
Grunberger, D., Banerjee, R., Eisinger, K., Oltz, E. M., Efros, L., Caldwell, M., et al. (1988). Preferential cytotoxicity on tumor cells by caffeic acid phenethyl ester isolated from propolis. Experientia 44, 230-232. doi: 10.1007/bf01941717

Gun, A., Ozer, M. K., Bilgic, S., Kocaman, N., and Ozan, G. (2016). Effect of caffeic acid phenethyl ester on vascular damage caused by consumption of high fructose corn syrup in rats. Oxid. Med. Cell Longev. 2016:3419479.

Gurel, A., Armutcu, F., Sahin, S., Sogut, S., Ozyurt, H., Gulec, M., et al. (2004). Protective role of $\alpha$-tocopherol and caffeic acid phenethyl ester on ischemiareperfusion injury via nitric oxide and myeloperoxidase in rat kidneys. Clin. Chim. Acta 339, 33-41. doi: 10.1016/j.cccn.2003.09.013

Hassan, N. A., El-Bassossy, H. M., Mahmoud, M. F., and Fahmy, A. (2014). Caffeic acid phenethyl ester, a 5-lipoxygenase enzyme inhibitor, alleviates diabetic atherosclerotic manifestations: effect on vascular reactivity and stiffness. Chem. Biol. Interact. 213, 28-36. doi: 10.1016/j.cbi.2014.01.019

Hishikawa, K., Nakaki, T., and Fujita, T. (2005). Oral flavonoid supplementation attenuates atherosclerosis development in apolipoprotein E-deficient mice. Arterioscler Thromb. Vasc. Biol. 25, 442-446. doi: 10.1161/01.atv.0000148404. 24271.fC

Ho, Y. J., Chen, W. P., Chi, T. C., Chang Chien, C. C., Lee, A. S., Chiu, H. L., et al. (2013). Caffeic acid phenethyl amide improves glucose homeostasis and attenuates the progression of vascular dysfunction in Streptozotocin-induced diabetic rats. Cardiovasc. Diabetol. 12, 1-11. doi: 10.5402/2011/519371

Horinouchi, T., Terada, K., Higashi, T., and Miwa, S. (2013). Endothelin receptor signaling: new insight into its regulatory mechanisms. J. Pharmacol. Sci. 123, 85-101. doi: $10.1254 /$ jphs.13r02cr

Huang, J., De Paulis, T., and May, J. M. (2004). Antioxidant effects of dihydrocaffeic acid in human EA.hy926 endothelial cells. J. Nutr. Biochem. 15, 722-729. doi: 10.1016/j.jnutbio.2004.07.002

Huang, P. L., Huang, Z., Mashimo, H., Bloch, K. D., Moskowitz, M. A., Bevan, J. A., et al. (1995). Hypertension in mice lacking the gene for endothelial nitric oxide synthase. Nature 377, 239-242.

Huang, S. S., Liu, S. M., Lin, S. M., Liao, P. H., Lin, R. H., Chen, Y. C., et al. (2005). Antiarrhythmic effect of caffeic acid phenethyl ester (CAPE) on myocardial ischemia/reperfusion injury in rats. Clin. Biochem. 38, 943-947. doi: 10.1016/j. clinbiochem.2005.07.003

Ilhan, A., Koltuksuz, U., Ozen, S., Uz, E., Ciralik, H., and Akyol, O. (1999). The effects of caffeic acid phenethyl ester (CAPE) on spinal cord ischemia/reperfusion injury in rabbits. Eur. J. Cardio Thoracic. Surg. 16, 458463. doi: 10.1016/s1010-7940(99)00246-8

Ilhan et al., S., Y1lmaz, N., Nacar, E., Motor, S., Oktar, S., and şahna, E. (2014). The effect of caffeic acid phenethyl ester on isoproterenol-induced myocardial injury in hypertensive rats. Anadolu Kardiyol Derg. 14, 576-582. doi: 10.5152/ akd.2014.4825

Inampudi, C., Akintoye, E., Ando, T., and Briasoulis, A. (2018). Angiogenesis in peripheral arterial disease. Curr. Opin. Pharmacol. 39, 60-67. doi: 10.1016/j. coph.2018.02.011

Ince, H., Kandemir, E., Bagci, C., Gulec, M., and Akyol, O. (2006). The effect of caffeic acid phenethyl ester on short-term acute myocardial ischemia. Med. Sci. Monit. 12, 187-193.

Information, T. (2015). ClinicalTrials.gov [Internet]. Bethesda (MD): National Library of Medicine (US).

Iraz, M., Fadillioğlu, E., Taşdemir, S., Ateş, B., and Erdoğan, S. (2005a). Dose dependent effects of caffeic acid phenethyl ester on heart rate and blood pressure in rats. Eur. J. Gen. Med. 2, 69-75.

Iraz, M., Fadillioglu, E., Tasdemir, S., and Erdogan, S. (2005b). Role of vagal activity on bradicardic, and. (hypotensive). effects of caffeic acid phenethyl ester (CAPE). Cardiovasc. Toxicol. 5, 391-396. doi: 10.1385/ct:5:4:391

Irmak, M. K., Koltuksuz, U., Kutlu, N. O., Yağmurca, M., Özyurt, H. I., Karaman, A., et al. (2001). The effect of caffeic acid phenethyl ester on ischemiareperfusion injury in comparison with $\alpha$-tocopherol in rat kidneys. Urol. Res. 29, 190-193. doi: $10.1007 / \mathrm{s} 002400100185$

Ishikawa, T., Hume, J. R., and Keef, K. D. (1993). Regulation of Ca2+ channels by cAMP and cGMP in vascular smooth muscle cells. Circ. Res. 73, 1128-1137. doi: 10.1161/01.res.73.6.1128

Ito, H., Gonthier, M.-P., Manach, C., Morand, C., Mennen, L., Rémésy, C., et al. (2005). Polyphenol levels in human urine after intake of six different polyphenol-rich beverages. Br. J. Nutr. 94, 500-509. doi: 10.1079/bjn20051522 
Izuta, H., Shimazawa, M., Tsuruma, K., Araki, Y., Mishima, S., and Hara, H. (2009). Bee products prevent VEGF-induced angiogenesis in human umbilical vein endothelial cells. BMC Complement Altern. Med. 9:45. doi: 10.1186/1472-68829-45

Johnson, T. A., Jinnah, H. A., and Kamatani, N. (2019). Shortage of cellular ATP as a cause of diseases and strategies to enhance ATP. Front. Pharmacol. 10:98. doi: 10.3389/fphar.2019.00098

Jung, J. E., Kim, H. S., Lee, C. S., Park, D. H., Kim, Y. N., Lee, M. J., et al. (2007). Caffeic acid and its synthetic derivative CADPE suppress tumor angiogenesis by blocking STAT3-mediated VEGF expression in human renal carcinoma cells. Carcinogenesis 28, 1780-1787. doi: 10.1093/carcin/bgm130

Jung, W. K., Choi, I., Lee, D. Y., Yea, S. S., Choi, Y. H., Kim, M. M., et al. (2008). Caffeic acid phenethyl ester protects mice from lethal endotoxin shock and inhibits lipopolysaccharide-induced cyclooxygenase- 2 and inducible nitric oxide synthase expression in RAW 264.7 macrophages via the p38/ERK and NF-кB pathways. Int. J. Biochem. Cell Biol. 40, 2572-2582. doi: 10.1016/j.biocel. 2008.05.005

Kamil Burgazli, M., Aydogdu, N., Rafiq, A., Mericliler, M., Chasan, R., and Erdogan, A. (2013). Effects of caffeic acid phenethyl ester (CAPE) on membrane potential and intracellular calcium in human endothelial cells. Eur. Rev. Med. Pharmacol. Sci. 17, 720-728.

Kart, A., Cigremis, Y., Ozen, H., and Dogan, O. (2009). Caffeic acid phenethyl ester prevents ovary ischemia/reperfusion injury in rabbits. Food Chem. Toxicol. 47, 1980-1984. doi: 10.1016/j.fct.2009.05.012

Kassim, M., Mansor, M., Kamalden, T. A., Shariffuddin, I. I., Hasan, M. S., Ong, G., et al. (2014). Caffeic acid Phenethyl ester (CAPE): scavenger of peroxynitrite in vitro and in sepsis models. Shock 42, 154-160. doi: 10.1097/ shk.0000000000000179

Kawashima, S., and Yokoyama, M. (2004). Dysfunction of endothelial nitric oxide synthase and atherosclerosis. Arterioscler Thromb. Vasc. Biol. 24, 998-1005. doi: 10.1161/01.atv.0000125114.88079.96

Kelly, R. A., Balligand, J.-L., and Smith, T. W. (2007). Nitric oxide and cardiac function. Life Sci. 81, 779-793.

Khan, F. A., Maalik, A., and Murtaza, G. (2016). Inhibitory mechanism against oxidative stress of caffeic acid. J. Food Drug Anal. 24, 695-702. doi: 10.1016/j. jfda.2016.05.003

Khan, M., Elango, C., Ansari, M. A., Singh, I., and Singh, A. K. (2007). Caffeic acid phenethyl ester reduces neurovascular inflammation and protects rat brain following transient focal cerebral ischemia. J. Neurochem. 102, 365-377. doi: 10.1111/j.1471-4159.2007.04526.x

Khanna, A., Cowled, P. A., and Fitridge, R. A. (2005). Nitric oxide and skeletal muscle reperfusion injury: current controversies (research review). J. Surg. Res. 128, 98-107. doi: 10.1016/j.jss.2005.04.020

Kim, Y. W., and Byzova, T. V. (2014). Oxidative stress in angiogenesis and vascular disease. Blood 123, 625-631. doi: 10.1182/blood-2013-09-512749

Koltuksuz, U., Irmak, M. K., Karaman, A., Var, E. U. A., Özyurt, H., and Akyol, O. (2000). Testicular nitric oxide levels after unilateral testicular torsion/detorsion in rats pretreated with caffeic acid phenethyl ester. Urol. Res. 28, 360-363. doi: $10.1007 / \mathrm{s} 002400000145$

Koltuksuz, U., Özen, S., Uz, E., Aydinç, M., Karaman, A., Gültek, A., et al. (1999). Caffeic acid phenethyl ester prevents intestinal reperfusion injury in rats. J. Pediatr. Surg. 34, 1458-1462. doi: 10.1016/s0022-3468(99)90103-3

Konishi, Y., Hitomi, Y., and Yoshioka, E. (2004). Intestinal absorption of p-coumaric and gallic acids in rats after oral administration. J. Agric. Food Chem. 52, 2527-2532. doi: 10.1021/jf035366k

Konishi, Y., and Kobayashi, S. (2004). Transepithelial transport of chlorogenic acid, caffeic acid, and their colonic metabolites in intestinal Caco-2 Cell monolayers. J. Agric. Food Chem. 52, 2518-2526. doi: 10.1021/jf035407c

Konishi, Y., Kobayashi, S., and Shimizu, M. (2003). Transepithelial transport of p-coumaric acid and gallic acid in Caco-2 cell monolayers. Biosci. Biotechnol. Biochem. 67, 2317-2324. doi: 10.1271/bbb.67.2317

Kono, Y., Kobayashi, K., Tagawa, S., Adachi, K., Ueda, A., Sawa, Y., et al. (1997). Antioxidant activity of polyphenolics in diets. Rate constants of reactions of chlorogenic acid and caffeic acid with reactive species of oxygen and nitrogen. Biochim. Biophys. Acta Gen. Subj. 1335, 335-342.

Ku, H. C., Lee, S. Y., Yang, K. C., Kuo, Y. H., and Su, M. J. (2016). Modification of caffeic acid with pyrrolidine enhances antioxidant ability by activating
AKT/HO-1 pathway in heart. PLoS One 11:e0148545. doi: 10.1371/journal. pone. 0148545

Kudugunti, S. K., Thorsheim, H., Yousef, M. S., Guan, L., and Moridani, M. Y. (2011). The metabolic bioactivation of caffeic acid phenethyl ester (CAPE) mediated by tyrosinase selectively inhibits glutathione S-transferase. Chem. Biol. Interact. 192, 243-256. doi: 10.1016/j.cbi.2011.03.015

Kudugunti, S. K., Vad, N. M., Whiteside, A. J., Naik, B. U., Yusuf, M. A., Srivenugopal, K. S., et al. (2010). Biochemical mechanism of caffeic acid phenylethyl ester (CAPE) selective toxicity towards melanoma cell lines. Chem. Biol. Interact. 188, 1-14. doi: 10.1016/j.cbi.2010.05.018

Kumaran, K. S., and Prince, P. S. M. (2010). Protective effect of caffeic acid on cardiac markers and lipid peroxide metabolism in cardiotoxic rats: an in vivo and in vitro study. Metabolism 59, 1172-1180. doi: 10.1016/j.metabol.2009.11. 010

Kuramoto, H., Hirao, K., Yumoto, H., Hosokawa, Y., Nakanishi, T., Takegawa, D., et al. (2019). Caffeic acid phenethyl ester (CAPE) induces VEGF expression and production in rat odontoblastic cells. Biomed. Res. Int. 2019:5390720.

Kuriyama, H., Ito, Y., and Suzuki, H. (1982). Factors modifying contractionrelaxation cycle in vascular smooth muscles. Am. J. Physiol. Hear. Circ. Physiol. 12, H641-H662.

Lafay, S., Morand, C., Manach, C., Besson, C., and Scalbert, A. (2006). Absorption and metabolism of caffeic acid and chlorogenic acid in the small intestine of rats. Br. J. Nutr. 96, 39-46. doi: 10.1079/bjn20061714

Laroux, F. S., Pavlick, K. P., Hines, I. N., Kawachi, S., Harada, H., Bharwani, S., et al. (1995). The role of nitric oxide in inflammation. Adv. Immunol. 60, 323-371.

Lee, S. Y., Ku, H. C., Kuo, Y. H., Chiu, H. L., and Su, M. J. (2015a). Pyrrolidinyl caffeamide against ischemia/reperfusion injury. (in). cardiomyocytes through AMPK/AKT pathways. J. Biomed. Sci. 22, 1-9.

Lee, S. Y., Ku, H. C., Kuo, Y. H., Yang, K. C., Tu, P. C., Chiu, H. L., et al. (2015b). Caffeic acid ethanolamide prevents cardiac dysfunction through sirtuin dependent cardiac bioenergetics preservation. J. Biomed. Sci. 22, 1-11. doi: 10.1186/s12929-015-0188-1

Leeya, Y., Mulvany, M. J., Queiroz, E. F., Marston, A., Hostettmann, K., and Jansakul, C. (2010). Hypotensive activity of an n-butanol extract and their purified compounds from leaves of Phyllanthus acidus (L.) Skeels in rats. Eur. J. Pharmacol. 649, 301-313. doi: 10.1016/j.ejphar.2010. 09.038

Li, D., and Mehta, J. L. (2000). Upregulation of endothelial receptor for oxidized LDL (LOX-1) by oxidized LDL and implications in apoptosis of coronary artery endothelial cells: evidence from use of antisense LOX-1 mRNA and chemical inhibitors. Arterioscler Thromb. Vasc. Biol. 20, 1116-1122. doi: 10.1161/01.atv. 20.4.1116

Li, D., Saldeen, T., Romeo, F., and Mehta, J. L. (2000). Oxidized LDL upregulates angiotensin II type 1 receptor expression in cultured human coronary artery endothelial cells: The potential role of transcription factor NF-кB. Circulation 102, 1970-1976. doi: 10.1161/01.cir.102.16.1970

Li, D., Wang, X., Huang, Q., Li, S., Zhou, Y., and Li, Z. (2018). Cardioprotection of CAPE-oNO2 against myocardial ischemia/reperfusion induced ROS generation via regulating the SIRT1/eNOS/NF-кB pathway in vivo and in vitro. Redox Biol. 15, 62-73. doi: 10.1016/j.redox.2017.11.023

Li, H., Wu, F., Tan, J., Wang, K., Zhang, C., Zheng, H., et al. (2016). Caffeic acid phenethyl ester exhibiting distinctive binding interaction with human serum albumin implies the pharmacokinetic basis of propolis bioactive components. J. Pharm. Biomed. Anal. 122, 21-28. doi: 10.1016/j.jpba.2016.01.040

Liao, H. F., Chen, Y. Y., Liu, J. J., Hsu, M. L., Shieh, H. J., Liao, H. J., et al. (2003). Inhibitory effect of caffeic acid phenethyl ester on angiogenesis, tumor invasion, and metastasis. J. Agric. Food Chem. 51, 7907-7912. doi: 10.1021/jf034729d

Lin, M. W., Yang, S. R., Huang, M. H., and Wu, S. N. (2004). Stimulatory actions of caffeic acid phenethyl ester, a known inhibitor of NF-кB activation, on Ca2+activated K+ current in pituitary GH3 cells. J. Biol. Chem. 279, 26885-26892. doi: 10.1074/jbc.m400356200

Long, Y., Han, M., Chen, J., Tian, X. Z., Chen, Q., and Wang, R. (2009). The vasorelaxant effect of caffeic acid phenethyl ester on porcine coronary artery ring segments. Vascul. Pharmacol. 51, 78-83. doi: 10.1016/j.vph.2009.03.002

Loscalzo, J., and Welch, G. (1995). Nitric oxide and its role in the cardiovascular system. Prog. Cardiovasc. Dis. 38, 87-104. doi: 10.1016/s0033-0620(05)80001-5 
Maffia, P., Ianaro, A., Pisano, B., Borrelli, F., Capasso, F., Pinto, A., et al. (2002). Beneficial effects of caffeic acid phenethyl ester in a rat model of vascular injury. Br. J. Pharmacol. 136, 353-360. doi: 10.1038/sj.bjp.0704720

Malhotra, R. (1998). Comparison of the cardiovascular effects of $2.5 \%$ phenylephrine and $10 \%$ phenylephrine during ophthalmic surgery. Eye 12, 973-975. doi: 10.1038/eye.1998.252

Malinski, T., Bailey, F., Zhang, Z. G., and Chopp, M. (1993). Nitric oxide measured by a porphyrinic microsensor in rat brain after transient middle cerebral artery occlusion. J. Cereb. Blood Flow Metab. 13, 355-358. doi: 10.1038/jcbfm.1993.48

Mansour, H. H., and Tawfik, S. S. (2012). Early treatment of radiation-induced heart damage in rats by caffeic acid phenethyl ester. Eur. J. Pharmacol. 692, 46-51. doi: 10.1016/j.ejphar.2012.06.037

Martini, D., Chiavaroli, L., González-Sarrías, A., Bresciani, L., Palma-Duran, S. A., Dall'asta, M., et al. (2019). Impact of foods and dietary supplements containing hydroxycinnamic acids on cardiometabolic biomarkers: a systematic review to explore inter-individual variability. Nutrients 11:1805. doi: 10.3390/ nu11081805

Mathew, S., Abraham, T. E., and Zakaria, Z. A. (2015). Reactivity of phenolic compounds towards free radicals under in vitro conditions. J. Food Sci. Technol. 52, 5790-5798. doi: 10.1007/s13197-014-1704-0

Mia, M. M., and Bank, R. A. (2016). The pro-fibrotic properties of transforming growth factor on human fibroblasts are counteracted by caffeic acid by inhibiting myofibroblast formation and collagen synthesis. Cell Tissue Res. 363, 775-789. doi: 10.1007/s00441-015-2285-6

Migliori, M., Cantaluppi, V., Mannari, C., Bertelli, A. A. E., Medica, D., Quercia, A. D., et al. (2015). Caffeic acid, a phenol found in white wine, modulates endothelial nitric oxide production and protects from oxidative stress-associated endothelial cell injury. PLoS One 10:e0117530. doi: 10.1371/ journal.pone. 0117530

Mollaoglu, H., Gokcimen, A., Ozguner, F., Oktem, F., Koyu, A., Kocak, A., et al. (2006). Caffeic acid phenethyl ester prevents cadmium-induced cardiac impairment in rat. Toxicology 227, 15-20. doi: 10.1016/j.tox.2006.06.020

Motawi, T. K., Darwish, H. A., and Abd El tawab, A. M. (2011). Effects of caffeic acid phenethyl ester on endotoxin-induced cardiac stress in rats: a possible mechanism of protection. J. Biochem. Mol. Toxicol. 25, 84-94. doi: 10.1002/ jbt.20362

Nagaoka, T., Banskota, A. H., Tezuka, Y., Midorikawa, K., Matsushige, K., and Kadota, S. (2003). Caffeic acid phenethyl ester (CAPE) analogues: potent nitric oxide inhibitors from the Netherlands propolis. Biol. Pharm. Bull. 26, 487-491. doi: 10.1248/bpb.26.487

Nardini, M., D’Aquino, M., Tomassi, G., Gentili, V., Di Felice, M., and Scaccini, C. (1995). Inhibition of human low-density lipoprotein oxidation by caffeic acid and other hydroxycinnamic acid derivatives. Free Radic. Biol. Med. 19, 541-552. doi: 10.1016/0891-5849(95)00052-y

Natarajan, K., Singh, S., Burke, T. R., Grunberger, D., and Aggarwal, B. B. (1996). Caffeic acid phenethyl ester is a potent and specific inhibitor of activation of nuclear transcription factor NF-кB. Proc. Natl. Acad. Sci. U.S.A. 93, 9090-9095. doi: 10.1073/pnas.93.17.9090

Oktar, S., Aydin, M., Yönden, Z., Alçin, E., Ilhan, S., and Nacar, A. (2010). Kafeik asit fenetil esterin siçanlarda isoproterenol indüklü miyokardiyal infarktüs üzerine etkileri. Anadolu Kardiyol. Derg. 10, 298-302.

Ozer, M. K., Parlakpinar, H., and Acet, A. (2004). Reduction of ischemiareperfusion induced myocardial infarct size in rats by caffeic acid phenethyl ester (CAPE). Clin. Biochem. 37, 702-705. doi: 10.1016/j.clinbiochem.2004. 01.012

Ozer, M. K., Parlakpinar, H., Cigremis, Y., Ucar, M., Vardi, N., and Acet, A. (2005a). Ischemia-. (reperfusion). leads to depletion of glutathione content and augmentation of malondialdehyde production in the rat heart from overproduction of oxidants: Can caffeic acid phenethyl ester (CAPE) protect the heart? Mol. Cell Biochem. 273, 169-175. doi: 10.1007/s11010-005-0551-8

Ozer, M. K., Parlakpinar, H., Vardi, N., Cigremis, Y., Ucar, M., and Acet, A. (2005b). Myocardial ischemia/reperfusion-induced oxidative renal damage in rats: Protection by caffeic acid phenethyl ester (Cape). Shock 24, 97-100. doi: 10.1097/01.shk.0000168525.97716.28

Özeren, M., Sucu, N., Tamer, L., Aytacoglu, B., Bayri, Ö, Döndaş, A., et al. (2005). Caffeic acid phenethyl ester (CAPE) supplemented St. Thomas' hospital cardioplegic solution improves the antioxidant defense system of rat myocardium during ischemia-reperfusion injury. Pharmacol. Res. 52, 258-263. doi: $10.1016 /$ j.phrs.2005.04.002

Ozguner, F., Altinbas, A., Ozaydin, M., Dogan, A., Vural, H., Kisioglu, A. N., et al. (2005). Mobile phone-induced myocardial oxidative stress: protection by a novel antioxidant agent caffeic acid phenethyl ester. Toxicol. Ind. Health 21, 223-230. doi: 10.1191/0748233705th228oa

Ozyurt, B., Iraz, M., Koca, K., Ozyurt, H., and Sahin, S. (2006). Protective effects of caffeic acid phenethyl ester on skeletal muscle ischemia-reperfusion injury in rats. Mol. Cell Biochem. 292, 197-203. doi: 10.1007/s11010-006-9232-5

Ozyurt, H., Ozyurt, B., Koca, K., and Ozgocmen, S. (2007). Caffeic acid phenethyl ester (CAPE) protects rat skeletal muscle against ischemia-reperfusion-induced oxidative stress. Vascul. Pharmacol. 47, 108-112. doi: 10.1016/j.vph.2007. 04.008

Paeng, S. H., Jung, W. K., Park, W. S., Lee, D. S., Kim, G. Y., Choi, Y. H., et al. (2015). Caffeic acid phenethyl ester reduces the secretion of vascular endothelial growth factor through the inhibition of the ROS, PI3K and HIF-1 $\alpha$ signaling pathways in human retinal pigment epithelial cells under hypoxic conditions. Int. J. Mol. Med. 35, 1419-1426. doi: 10.3892/ijmm.2015.2116

Paracatu, L. C., Faria, C. M. Q. G., Quinello, C., Rennó, C., Palmeira, P., Zeraik, M. L., et al. (2014). Caffeic acid phenethyl ester: consequences of its hydrophobicity in the oxidative functions and cytokine release by leukocytes. Evid. Based Complement Altern. Med. 2014:793629.

Parlakpinar, H., Sahna, E., Acet, A., Mizrak, B., and Polat, A. (2005). Protective effect of caffeic acid phenethyl ester (CAPE) on myocardial ischemiareperfusion-induced apoptotic cell death. Toxicology 209, 1-14. doi: 10.1016/j. tox.2004.10.017

Potente, M., and Carmeliet, P. (2017). The link between angiogenesis and endothelial metabolism. Annu. Rev. Physiol. 79, 43-66. doi: 10.1146/annurevphysiol-021115-105134

Que, X., Hung, M., Yeang, C., Gonen, A., Prohaska, T. A., Sun, X., et al. (2018). Oxidized phospholipids are proinflammatory and proatherogenic in hypercholesterolemic mice. Nature 558, 301-306. doi: 10.1038/s41586-0180198-8

Quintero-Fabián, S., Arreola, R., Becerril-Villanueva, E., Torres-Romero, J. C., Arana-Argáez, V., Lara-Riegos, J., et al. (2019). Role of matrix metalloproteinases in angiogenesis and cancer. Front. Oncol. 9:1370. doi: 10.3389/fonc. 2019.01370

Ren, J., Zhang, N., Liao, H., Chen, S., Xu, L., Li, J., et al. (2017). Caffeic acid phenethyl ester attenuates pathological cardiac hypertrophy by regulation of MEK/ERK signaling pathway in vivo and vitro. Life Sci. 181, 53-61. doi: 10.1016/j.lfs.2017.04.016

Roos, T. U., Heiss, E. H., Schwaiberger, A. V., Schachner, D., Sroka, I. M., Oberan, T., et al. (2011). Caffeic acid phenethyl ester inhibits PDGF-induced proliferation of vascular smooth muscle cells via activation of p38 MAPK, HIF-1 $\alpha$, and heme oxygenase-1. J. Nat. Prod. 74, 352-356. doi: 10.1021/np10 $0724 \mathrm{f}$

Russo, A., Longo, R., and Vanella, A. (2002). Antioxidant activity of propolis: role of caffeic acid phenethyl ester and galangin. Fitoterapia 73(Suppl. 1), 21-29.

Saavedra-Lopes, M., Ramalho, F. S., Ramalho, L. N. Z., Andrade-Silva, A., Martinelli, A. L. C., Jordão, A. A., et al. (2008). The protective effect of CAPE on hepatic ischemia/reperfusion injury in rats. J. Surg. Res. 150, 271-277. doi: 10.1016/j.jss.2008.01.039

Sato, Y., Itagaki, S., Kurokawa, T., Ogura, J., Kobayashi, M., Hirano, T., et al. (2011). In vitro and in vivo antioxidant properties of chlorogenic acid and caffeic acid. Int. J. Pharm. 403, 136-138. doi: 10.1016/j.ijpharm.2010.09.035

Shen, H., Tong, X., Yang, J., Yu, L., Zhou, H., Wang, Y., et al. (2020). Biotransformation of natural hydroxycinnamic acids by gut microbiota from normal and cerebral ischemia-reperfusion injured rats: a comparative study. Food Funct. 11, 5389-5395. doi: 10.1039/d0fo00775g

Shi, Y., Wu, X., Gong, Y., Qiu, Y., Zhang, H., Huang, Z., et al. (2010). Protective effects of caffeic acid phenethyl ester on retinal ischemia/reperfusion injury in rats. Curr. Eye Res. 35, 930-937. doi: 10.3109/02713683.2010.494820

Shieh, D. B., Yang, S. R., Shi, X. Y., Wu, Y. N., and Wu, S. N. (2005). Properties of BK Ca channels in oral keratinocytes. J. Dent. Res. 84, 468-473.

Silva, T., Oliveira, C., and Borges, F. (2014). Caffeic acid derivatives, analogs and applications: a patent review (2009-2013). Expert Opin. Ther. Pat. 24, 1257-1270. doi: 10.1517/13543776.2014.959492 
Son, S., and Lewis, B. A. (2002). Free radical scavenging and antioxidative activity of caffeic acid amide and ester analogues: structure-activity relationship. J. Agric. Food Chem. 50, 468-472. doi: 10.1021/jf010830b

Song, Y. S., Park, E. H., Hur, G. M., Ryu, Y. S., Lee, Y. S., Lee, J. Y., et al. (2002). Caffeic acid phenethyl ester inhibits nitric oxide synthase gene expression and enzyme activity. Cancer Lett. 175, 53-61. doi: 10.1016/s0304-3835(01)00787-x

Sorriento, D., Trimarco, B., and Iaccarino, G. (2011). Adrenergic mechanism in the control of endothelial function. Transl. Med. UniSa 1, 213-228.

Sova, M., and Saso, L. (2020). Natural sources, pharmacokinetics, biological activities and health benefits of hydroxycinnamic acids and their metabolites. Nutrients 12,1-30. doi: 10.1201/9780429321115-1

Sud'ina, G. F., Mirzoeva, O. K., Pushkareva, M. A., Korshunova, G. A., Sumbatyan, N. V., and Varfolomeev, S. D. (1993). Caffeic acid phenethyl ester as a lipoxygenase inhibitor with antioxidant properties. FEBS Lett. 329, 21-24. doi: 10.1016/0014-5793(93)80184-v

Sumners, C., De Kloet, A. D., Krause, E. G., Unger, T., and Steckelings, U. M. (2015). Angiotensin type 2 receptors: blood pressure regulation and end organ damage. Curr. Opin. Pharmacol. 21, 115-121. doi: 10.1016/j.coph.2015.01.004

Tahergorabi, Z., and Khazaei, M. (2012). A review on angiogenesis and its assays. Iran. J. Basic Med. Sci. 15, 1110-1126.

Tan, J., Ma, Z., Han, L., Du, R., Zhao, L., Wei, X., et al. (2005). Caffeic acid phenethyl ester possesses potent cardioprotective effects in a rabbit model of acute myocardial ischemia-reperfusion injury. Am. J. Physiol. Hear Circ. Physiol. 289, 2265-2271.

Tang, C., and Sojinu, O. S. (2012). Simultaneous determination of caffeic acid phenethyl ester and its metabolite caffeic acid in dog plasma using liquid chromatography tandem mass spectrometry. Talanta 94, 232-239. doi: 10. 1016/j.talanta.2012.03.029

Taubert, D., Berkels, R., Klaus, W., and Roesen, R. (2002). Nitric oxide formation and corresponding relaxation of porcine coronary arteries induced by plant phenols: essential structural features. J. Cardiovasc. Pharmacol. 40, 701-713. doi: 10.1097/00005344-200211000-00008

Teixeira, J., Gaspar, A., Garrido, E. M., Garrido, J., and Borges, F. (2013). Hydroxycinnamic acid antioxidants: an electrochemical overview. Biomed. Res. Int. 2013:251754.

Teke, Z., Bostanci, E. B., Yenisey, C., Kelten, E. C., Sacar, M., Simsek, N. G., et al. (2013). Caffeic acid phenethyl ester prevents detrimental effects of remote ischemia-reperfusion injury on healing of colonic anastomoses. J. Investig. Surg. 26, 16-29. doi: 10.3109/08941939.2012.687434

Teke, Z., Bostanci, E. B., Yenisey, C., Sacar, M., Simsek, N. G., and Akoglu, M. (2012). Caffeic acid phenethyl ester alleviates mesenteric ischemia/reperfusion injury. J. Investig. Surg. 25, 354-365. doi: 10.3109/08941939.2012.677968

Totan, Y., Aydln, E., Çekiç, O., Daglloglu, M. C., Borazan, M., Daglloglu, K., et al. (2001). Effect of caffeic acid phenethyl ester on corneal neovascularization in rats. Curr. Eye Res. 23, 291-297. doi: 10.1076/ceyr.23.4.291.5453

Tsai, S. J., Chao, C. Y., and Yin, M. C. (2011). Preventive and therapeutic effects of caffeic acid against inflammatory injury in striatum of MPTP-treated mice. Eur. J. Pharmacol. 670, 441-447. doi: 10.1016/j.ejphar.2011.09.171

Tsai, S. K., Lin, M. J., Liao, P. H., Yang, C. Y., Lin, S. M., Liu, S. M., et al. (2006). Caffeic acid phenethyl ester ameliorates cerebral infarction in rats subjected to focal cerebral ischemia. Life Sci. 78, 2758-2762. doi: 10.1016/j.lfs.2005.10.017

Turkseven, S., Kruger, A., Mingone, C. J., Kaminski, P., Inaba, M., Rodella, L. F., et al. (2005). Antioxidant mechanism of heme oxygenase-1 involves an increase in superoxide dismutase and catalase in experimental diabetes. Am. J. Physiol. Hear. Circ. Physiol. 289, 701-707.

Verbrugge, F. H., Tang, W. H. W., and Hazen, S. L. (2015). Protein carbamylation and cardiovascular disease. Kidney Int. 88, 474-478. doi: 10.1038/ki.2015.166

Verma, S., Fedak, P. W. M., Weisel, R. D., Butany, J., Rao, V., Maitland, A., et al. (2002). Fundamentals of reperfusion injury for the clinical cardiologist. Circulation 105, 2332-2336. doi: 10.1161/01.cir.0000016602.96363.36

Vieira, O., Escargueil-Blanc, I., Meilhac, O., Basile, J. P., Laranjinha, J., Almeida, L., et al. (1998). Effect of dietary phenolic compounds on apoptosis of human cultured endothelial cells induced by oxidized LDL. Br. J. Pharmacol. 123, 565-573. doi: 10.1038/sj.bjp.0701624

Wallerath, T., Li, H., Gödtel-Ambrust, U., Schwarz, P. M., and Förstermann, U. (2005). A blend of polyphenolic compounds explains the stimulatory effect of red wine on human endothelial NO synthase. Nitric Oxide Biol. Chem. 12, 97-104. doi: 10.1016/j.niox.2004.12.004
Wang, F., and Yang, J. (2012). A comparative study of caffeic acid and a novel caffeic acid conjugate SMND-309 on antioxidant properties in vitro. LWT Food Sci. Technol. 46, 239-244. doi: 10.1016/j.lwt.2011.09.025

Wang, L. C., Lin, Y. L., Liang, Y. C., Yang, Y. H., Lee, J. H., Yu, H. H., et al. (2009). The effect of caffeic acid phenethyl ester on the functions of human monocyte-derived dendritic cells. BMC Immunol. 10:39. doi: 10.1186/14712172-10-39

Wang, T., Chen, L., Wu, W., Long, Y., and Wang, R. (2008). Potential cytoprotection: antioxidant defence. (by). caffeic acid phenethyl ester against free radical-induced damage of lipids, DNA, and proteins. Can. J. Physiol. Pharmacol. 86, 279-287. doi: 10.1139/y08-029

Wang, X., Bowman, P. D., Kerwin, S. M., and Stavchansky, S. (2007). Stability of caffeic acid phenethyl ester and its fluorinated derivative in rat plasma. Biomed. Chromatogr. 21, 343-350. doi: 10.1002/bmc.737

Wang, X., Li, D., Fan, L., Xiao, Q., Zuo, H., and Li, Z. (2017). CAPE-pNO2 ameliorated diabetic nephropathy through regulating the Akt/NF-kB/ iNOS pathway in STZ-induced diabetic mice. Oncotarget 8, 114506-114525. doi: 10.18632/oncotarget.23016

Wang, X., Pang, J., Maffucci, J. A., Pade, D. S., Newman, R. A., Kerwin, S. M., et al. (2009). Pharmacokinetics of caffeic acid phenethyl ester, and its catecholring. (fluorinated). derivative following intravenous administration to rats. Biopharm. Drug. Dispos. 30, 221-228. doi: 10.1002/bdd.657

Wang, X., Stavchansky, S., Bowman, P. D., and Kerwin, S. M. (2006). Cytoprotective effect of caffeic acid phenethyl ester (CAPE) and catechol ringfluorinated CAPE derivatives against menadione-induced oxidative stress in human endothelial cells. Bioorganic. Med. Chem. 14, 4879-4887. doi: 10.1016/ j.bmc.2006.03.015

Wang, X., Stavchansky, S., Kerwin, S. M., and Bowman, P. D. (2010). Structureactivity relationships in the cytoprotective effect of caffeic acid phenethyl ester (CAPE) and fluorinated derivatives: effects on heme oxygenase-1 induction and antioxidant activities. Eur. J. Pharmacol. 635, 16-22. doi: 10.1016/j.ejphar.2010. 02.034

Wang, X., Stavchansky, S., Zhao, B., Bynum, J. A., Kerwin, S. M., and Bowman, P. D. (2008). Cytoprotection of human endothelial cells from menadione cytotoxicity by caffeic acid phenethyl ester: the role of heme oxygenase-1. Eur. J. Pharmacol. 591, 28-35. doi: 10.1016/j.ejphar.2008.06.017

Watanabe, T., Nakao, A., Emerling, D., Hashimoto, Y., Tsukamoto, K., Horie, Y., et al. (1994). Prostaglandin $\mathrm{F}(2 \alpha)$ enhances tyrosine phosphorylation and DNA synthesis through phospholipase C-coupled receptor via Ca2+-dependent intracellular pathway in NIH-3T3 cells. J. Biol. Chem. 269, 17619-17625.

Wei, X., Zhao, L., Ma, Z., Holtzman, D. M., Yan, C., Dodel, R. C., et al. (2004). Caffeic acid phenethyl ester prevents neonatal hypoxic-ischaemic brain injury. Brain 127, 2629-2635. doi: 10.1093/brain/awh316

Weidinger, A., and Kozlov, A. V. (2015). Biological activities of reactive oxygen and nitrogen species: oxidative stress versus signal transduction. Biomolecules 5, 472-484. doi: 10.3390/biom5020472

Weng, Y. C., Chuang, S. T., Lin, Y. C., Chuang, C. F., Chi, T. C., Chiu, H. L., et al. (2012). Caffeic acid phenylethyl amide protects against the metabolic consequences in diabetes mellitus induced by diet and streptozocin. Evid. Based Complement Altern. Med. 2012:984780.

Wu, J., Omene, C., Karkoszka, J., Bosland, M., Eckard, J., and Klein, C. B. (2011). Caffeic acid phenethyl ester (CAPE), derived from a honeybee product propolis, exhibits a diversity of anti-tumor effects in preclinical models of human breast cancer. Cancer Lett. 308:2011.

Wu, M. Y., Yiang, G. T., Liao, W. T., Tsai, A. P. Y., Cheng, Y. L., Cheng, P. W., et al. (2018). Current mechanistic concepts in ischemia and reperfusion injury. Cell Physiol. Biochem. 46, 1650-1667.

Wu, S., Zhang, K., Qin, H., Niu, M., Zhao, W., Ye, M., et al. (2017). Caffeic acid phenethyl ester (CAPE) revisited: covalent modulation of XPO1/CRM1 activities and implication for its mechanism of action. Chem. Biol. Drug Des. 89, 655-662. doi: $10.1111 /$ cbdd. 12905

Wu, W. M., Lu, L., Long, Y., Wang, T., Liu, L., Chen, Q., et al. (2007). Free radical scavenging and antioxidative activities of caffeic acid phenethyl ester (CAPE) and its related compounds in solution and membranes: a structure-activity insight. Food Chem. 105, 107-115. doi: 10.1016/j.foodchem.2007.03.049

Yan-Chun, Z., and Rong-Liang, Z. (1991). Phenolic compounds and an analog as superoxide anion scavengers and anti oxidants. Biochem. Pharmacol. 42, 1177-1179. doi: 10.1016/0006-2952(91)90251-y 
Yang, J., Kerwin, S. M., Bowman, P. D., and Stavchansky, S. (2012). Stability of caffeic acid phenethyl amide (CAPA) in rat plasma. Biomed. Chromatogr. 26, 594-598. doi: 10.1002/bmc.1702

Yang, J., Marriner, G. A., Wang, X., Bowman, P. D., Kerwin, S. M., and Stavchansky, S. (2010). Synthesis of a series of caffeic acid phenethyl amide (CAPA) fluorinated derivatives: comparison of cytoprotective effects to caffeic acid phenethyl ester (CAPE). Bioorganic Med. Chem. 18, 5032-5038. doi: 10.1016/ j.bmc.2010.05.080

Yang, Q., He, G. W., Underwood, M. J., and Yu, C. M. (2016). Cellular and molecular mechanisms of endothelial ischemia/reperfusion injury: perspectives and implications for postischemic myocardial protection. Am. J. Transl. Res. 8, 765-777.

Yasuko, K., Tomohiro, N., Sei-Itsu, M., Ai-Na, L., Yasuo, F., and Takashi, T. (1984). Caffeic acid is a selective inhibitor for leukotriene biosynthesis. Biochim. Biophys. Acta (BBA) Lipids Lipid Metab. 792, 92-97. doi: 10.1016/00052760(84)90287-x

Yeǧin, M. E., Bilkay, U., Tiftikçioğlu, Y. Ö, Uyanikgil, Y., Çavuşğlu, T., Ercan, G., et al. (2020). Altering effects of caffeic acid phenethyl ester (CAPE) and ischemia/reperfusion injury: an experimental study in a rat TRAM flap model. Eur. J. Plast. Surg. 43, 527-534. doi: 10.1007/s00238-020-01637-9

Yellon, D. M., and Hausenloy, D. J. (2007). Myocardial reperfusion injury. N. Engl. J. Med. 357, 2408-2410.

Yokozawa, T., Zhou, J. J., Oura, H., Tanaka, T., Nonaka, G. -I., and Nishioka, I. (1995). Effects on blood pressure of caffeic acid analogues isolated from Salviae Miltiorrhizae Radix in rats with adenine-induced renal hypertension. Phyther. Res. 9, 105-109. doi: 10.1002/ptr.2650090205
Zhang, J., Xu, L. X., Xu, X. S., Li, B. W., Wang, R., and Fu, J. J. (2014). Synthesis and effects of new caffeic acid derivatives on nitric oxide production in lipopolysaccharide-induced RAW 264.7 macrophages. Int. J. Clin. Exp. Med. 7, 1022-1027.

Zhang, P., Tang, Y., Li, N. G., Zhu, Y., and Duan, J. A. (2014). Bioactivity, and chemical synthesis of caffeic acid phenethyl ester, and its derivatives. Molecules 19, 16458-16476. doi: 10.3390/molecules191016458

Zhou, Y., Fang, S. H., Ye, Y. L., Chu, L. S., Zhang, W. P., Wang, M. L., et al. (2006). Caffeic acid ameliorates early and delayed brain injuries after focal cerebral ischemia in rats. Acta Pharmacol. Sin. 27, 1103-1110. doi: 10.1111/j.1745-7254. 2006.00406.x

Zhu, H., Chen, S., Hao, S., Zhang, Z., Wang, W., and Yao, S. (2006). Double roles of hydroxycinnamic acid derivatives in protection against lysozyme oxidation. Biochim. Biophys. Acta Gen. Subj. 1760, 1810-1818. doi: 10.1016/j.bbagen.2006. 08.007

Conflict of Interest: The authors declare that the research was conducted in the absence of any commercial or financial relationships that could be construed as a potential conflict of interest.

Copyright $(2020$ Silva and Lopes. This is an open-access article distributed under the terms of the Creative Commons Attribution License (CC BY). The use, distribution or reproduction in other forums is permitted, provided the original author(s) and the copyright owner(s) are credited and that the original publication in this journal is cited, in accordance with accepted academic practice. No use, distribution or reproduction is permitted which does not comply with these terms. 